\title{
Murburn precepts for cytochrome P450 mediated drug/xenobiotic metabolism
}

\author{
Abhinav Parashar ${ }^{1,2} \&$ Kelath Murali Manoj $*^{1}$ \\ *Corresponding author, ${ }^{1}$ Satyamjayatu: The Science \& Ethics Foundation, \\ Snehatheeram, Kulappully, Shoranur-2 (PO), Kerala, India-679122. \\ murman@satyamjayatu.com \\ *Corresponding author, ${ }^{2}$ Department of Biotechnology, \\ Vignan's Foundation for Science, Technology \& Research, Vadlamudi, Guntur, India-522213. \\ parashar.abhinav.2008@gmail.com
}

\begin{abstract}
Herein, we demonstrate why deeming diffusible reactive oxygen species (DROS) as toxic wastes does not afford a comprehensive understanding of cytochrome P450 mediated microsomal xenobiotic metabolism $(\mathrm{mXM})$. Using the recent insights unveiled in mechanistic redox enzymology, we reason out the remaining pieces of the $\mathrm{mXM}$ mechanistic chemistry and support our proposals with visual evidence and thermodynamic calculations. Particularly, we elucidate how murburn model better explains- (i) promiscuity of the unique P450-reductase; (ii) prolific activity and inhibitions of CYP3A4; (iii) structure-function correlations of important key CYP2 family isozymes- 2C9, 2D6 and 2E1; and (iv) mutation studies and mechanism-based inactivation of CYPs. In the light of our findings, it is opportune to revamp the methodologies employed for screening potential drug candidate from lead molecules.
\end{abstract}

Keywords: cytochrome P450 (CYP); murburn concept; drug/xenobiotic metabolism; pharmacokinetics; diffusible reactive oxygen species (DROS); 


\section{Introduction}

Redox processes are pivotal to the maintenance of cellular function and coordination of life activities. In this context, the mainstream view predominantly considers diffusible reactive oxygen species (DROS) as toxic wastes or at the best, molecular signals or destructive agents in pathophysiology. This purview is aesthetically appealing and vitally deterministic, and therefore congenial to the 'order-seeking' classical systemic perspective. For cytochrome P450 (CYP) family of heme-thiolate enzymes, the interactive paradigm of various redox proteins and additives/substrates are perceived to occur only via high affinity binding based outcomes (de Montellano 2015). Such a 'topographical recognition' is considered essential for deterministic mechanistic explanations involving Marcus' outer sphere long range electron transfers and/or oxygen-rebound at hemeFe-centers, via key CYP transition state intermediate like Compound I (de Montellano 2015). Murburn concept is a new mechanistic perspective in redox enzymology proposed for explaining the mechanism and versatility of electron-/moiety-transfer reactions mediated by heme-enzymes like CPO (chloroperoxidase), HRP (horseradish peroxidase), CYPs, mitochondrial Complexes III/IV, etc. and flavo-enzymes like CPR (cytochrome P450 reductase) and Complexes I /II of mitochondria (Kelath Murali Manoj and Hager 2001; K M Manoj 2006; K M Manoj and Hager 2008; K M Manoj et al. 2010; K M Manoj, Gade, and Mathew 2010; Andrew, Hager, and Manoj 2011; Parashar and Manoj 2012; Gade, Bhattacharya, and Manoj 2012; Parashar, Gade, et al. 2014; Parashar, Venkatachalam, et al. 2014; Kelath Murali Manoj, Gade, et al. 2016; Kelath Murali Manoj, Parashar, Venkatachalam, et al. 2016; Kelath Murali Manoj, Venkatachalam, and Parashar 2016; Kelath Murali Manoj, Parashar, Gade, et al. 2016; Venkatachalam, Parashar, and Manoj 2016; Parashar, Gideon, and Manoj 2018; Kelath Murali Manoj, Parashar, et al. 2019; Kelath Murali Manoj, Soman, et al. 2019; Kelath Murali Manoj and Bazhin 2019; Kelath Murali Manoj and Soman 2020; Kelath Murali Manoj, Ramasamy, et al. 2020). It advocates that some routine cellular metabolism and physiology processes are achieved by stabilizing/utilizing DROS. The murburn purview does not rule out substrate/ligand binding at the heme-pocket, but advocates that there could be several non-specific modalities of binding substrates on various loci on/within the CYP, in order to increase the probability of the substrates' reactions/interactions with DROS (Figure 1).

\section{Methodology}


Herein, we employ in silico approaches (Venkatachalam, Parashar, and Manoj 2016; Morris et al. 2009; DeLano 2002; Pettersen et al. 2004; Yu et al. 2010; Tian et al. 2018; O'Boyle et al. 2011) murburn reaction chemistry logic (Kelath Murali Manoj, Parashar, Venkatachalam, et al. 2016; Kelath Murali Manoj and Soman 2020) and thermodynamic calculations (Kelath Murali Manoj, Soman, et al. 2019; Kelath Murali Manoj and Bazhin 2019; Bazhin 2020) to elucidate the new model of CYP-mediated drug metabolism and ground the theoretical foundations to explain experimental observations. The PDB IDs of the crystal structures of CYPs used herein are as follows: 1A1 (4I8V; (Walsh, Szklarz, and Scott 2013)), 1A2 (2HI4; (Sansen et al. 2007)), 1B1 (3PM0; (A Wang et al. 2011)), 2A6 (2FDV; (Jason K. Yano et al. 2006)), 2A13 (3T3S; (DeVore et al. 2012)), 2B6 (4RQL; (Shah et al. 2015)), 2C8 (1PQ2; (Schoch et al. 2004)), 2C9 (1R9O; (Wester et al. 2004), 1OG5; (Williams et al. 2003)), 2C19 (4GQS; (Reynald et al. 2012)), 2 D6 (4WNV; (An Wang et al. 2015)), 2E1 (3E6I; (Porubsky, Meneely, and Scott 2008)), 2R1 (3CZH; (Strushkevich et al. 2008)), 3A4 (3NXU; (Sevrioukova and Poulos 2010), 1TQN; (J K Yano et al. 2004)), 3A5 (6MJM; (Hsu and Johnson 2019)), 19A1 (3S79; (Ghosh et al. 2012)), CPO (1CPO; (Sundaramoorthy, Terner, and Poulos 1995)), P450 cam (2CPP; (Poulos, Finzel, and

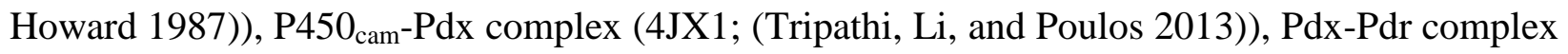
(3LB8; (Sevrioukova, Poulos, and Churbanova 2010)), P450-BM3 (1BVY; Sevrioukova et al. 2010).

\section{Results and Discussion}

The camphor metabolizing system of Pseudomonas putida and the fatty acid hydroxylating complex from Bacillum megaterium became the role models for human liver microsomal CYPs (de Montellano 2015, Honeychurch et al. 1999, Cryle et al. 2007). The Pseudomonas system comprises of soluble heme-thiolate enzyme CYP101 (P450cam of 414 aa, $47.36 \mathrm{kDa}$ ), putidaredodoxin (Pdx, an Fe-S protein of 106 aa, $11.60 \mathrm{kDa})$ and putidaredoxin reductase (PdR, a flavoenzyme of 420 aa, $47.57 \mathrm{kDa}$ ). They are respectively analogous to membrane-bound liver microsomal CYPs (of 450-500 aa, 50-60 kDa), cytochrome $b_{5}$ (Cyt. $b_{5}$, of 134 aa, $15.33 \mathrm{kDa}$ ) and their unique diflavoenzyme reductase (CPR, of 677 aa, $76.69 \mathrm{kDa})$. (The membrane-bound Bacillus CYP102 or P450BM3 is a complex protein of 1049 aa, $117.78 \mathrm{kDa}$; comprising both heme and flavin modules fused into one.) The classical mechanism entails multi-molecular 
sequential complexations: Pd/CPR must bind to NADH/NADPH to get reduced and this reduced enzyme-substrate complex binds to $\mathrm{Pdx} / \mathrm{Cyt} . b_{5}$, to reduce the latter protein(s). Then, $\mathrm{Pdx} / \mathrm{Cyt}$. $b_{5}$ detaches or complexes with a CYP molecule, which has a substrate molecule bound at the distal pocket (this bound stature is necessary to alter the spin state of heme-Fe and increase its redox potential), to transfer one electron. Now, the heme-Fe is capable of binding a molecule of triplet oxygen. Subsequently, the classical mechanistic cycle seeks yet another cascade of such deterministic protein-protein complexation mediated electron transfers to explain the formation of Compound I (a 2e deficient species that carries out oxygen-rebound at the heme center), or loss of redox equivalents by formation of water and peroxide at the heme center (de Montellano 2015). Analysing the structures of the reported proteins, protein-substrate and protein-protein complexation models (Supplementary Information File, Item 1) revealed several requirements lacking for the operational fecundity of the classical mechanism within the liver microsomal CYPs. Most importantly, the classical model is a highly fastidious and deterministic scheme, which does not appeal to the evolutionary mandates for xenobiotic metabolism. As the diverse substrates are 'unknown' to the organism (as they have little metabolic evolutionary history) and are non-inducible with most of their substrates, it is unlikely that diverse substrates could have deterministic recognition mechanisms and binding affinities for the enzymes that metabolize them. We reasoned that since the reactions catalyzed by the extracellular heme-thiolate enzymes of chloroperoxidase and CYPs are similar, they could have common mechanistic principles and this thought-line was helpful in understanding the latter system. On the same token, since both microsomal and mitochondrial redox metabolic systems employ heme/flavin enzymes housed within phospholipid membranes, and use reduced nicotinamide equivalents in conjunction with molecular oxygen as oxidant, they would most likely employ similar mechanistic strategies. The reaction profiles of the two systems are also astonishingly similar, showing an enhanced oxygen consumption rate by virtue of the presence of substrates (Figure 2). Noting such structural and observational similarities (Kelath Murali Manoj, Gideon, et al. 2020), we propose the murburn model equations shown in Figure 2. The new bi-molecular parallel scheme of reactions is parsimonious and supported by the fact that substrate-bound activation concept is irrelevant in mitochondrial membrane complexes and trans-membrane potential is irrelevant in microsomal reactions. Only, DROS-mediated reactions and their susceptibility to interfacial proton dynamics explain the common mechanistic underpinnings of thermodynamics and kinetics. The 
thermodynamic pull exerted by the presence of substrate (by virtue of $\mathrm{O}-\mathrm{H}$ bond formation; whether in $\mathrm{ROH}, \mathrm{H}_{2} \mathrm{O}$ or $\mathrm{H}_{2} \mathrm{O}_{2}$ ) and the enhanced reactivity/rates afforded by ${ }^{1} \mathrm{O}_{2}$ and high $\Delta_{\mathrm{r}} G^{\prime \mathrm{o}}$ aq (transformed Gibbs free energy) afforded by substrates' presence explains the enhanced rates within the system in state 3 (Figure 2). Earlier, it was misunderstood (resulting from some coincidental observations from the P450cam system) that substrate binding at heme distal pocket is essential to alter spin state and redox potential of the CYP, enabling it to receive electrons from CPR via protein-protein complexation. (We don't negate that in some CYP+substrate combinations taken at high concentrations, substrate binding could enhance spin shifts, like the P450cam system. But we question the viability of electron transfer through protein-protein binding and obligatory catalysis of all substrates by Compound I's oxygen-rebound modality at the heme distal pocket.) Quite contrastingly, murburn scheme posits that since triplet oxygen cannot activate/react with flavins/nicotinamides efficiently and CYPs' high spin heme-Fe can generate singlet oxygen more efficiently from superoxide, DROS could serve as effective connectivity between the two systems (CPR sends superoxide and CYP sends singlet oxygen). Only select four-steps reaction scheme with superoxide as the key agent is shown in Figure 2, whereas the physiological reaction may have several DROS competitive interactions and products can be formed in several modalities (Supplementary File, Item 2). In this regard, Table 1 presents the salient mechanistic differences between classical and murburn models and the advancements made in interpretations of theoretical assumptions/explanations to account for experimental observations.

While the classical model assumes that F \& G helices of the CYPs open up to accommodate the diverse substrates in the distal heme pocket (to explain for the fact that some large molecules are too big to access the Fe-center through distal channels, with respect to the crystal structure of the pertinent CYP), the assumption fails to explain why then some substrates are not preferred by that very CYP. The obligatory involvement of "outside the active site DROS-reaction networks" explains the myriads of publications reporting vast diversity of substrate preferences, kinetic isotope effects, lack of enantioselectivity in hydroxylations in the vast majority of reactions catalyzed by CYPs, drug-drug interactions, reaction activations by certain additives, substrate inhibitions at high concentrations, atypical kinetics, variable and non-integral stoichiometries, inhibitory effects at high concentrations of cyt. $b_{5}$, secondary hydroxylations, etc. In Table S4 of 
our earlier communication (Kelath Murali Manoj, Parashar, Gade, et al. 2016), we had elaborated how the murburn model better explains at least 50 distinct theoretical and observational aspects of the microsomal reaction systems whereas the classical model fails or makes contrasting/ambiguous predictions. Notwithstanding, we proceed to elaborate upon some pressing and important aspects regarding CYP-mediated liver microsomal drug metabolism.

\section{How is the promiscuity of the lone CPR interacting and transferring electrons to a bevy of CYP isoforms (of diverse topography and electrostatic features) explained?}

Quite unlike chloroperoxidase (a control heme-thiolate protein), whose proximal cysteine is buried within the protein core, liver microsomal CYPs show solvent-accessible cysteine (hemeFe axial ligand) within a crypt, when viewed from the proximal side (Figure 3). Heme, colored in bright red-orange, is visible from the proximal side only in CYP2A6 and in CYP2E1. The surface topographies of the proximal side vary considerably, as is evident from a visual survey of the proteins. This facet of liver microsomal CYPs' structure does not agree well with the classical mechanism that vouches for CPR/Cyt. $b_{5}$ complex driving the electron to heme-center via unfavourable redox gradients and distances. However, it supports the possibilities for ease in non-specific reducibility by diffusible species. The solvent-accessibility or proximal cysteine must be a feature to facilitate the facile formation of $\mathrm{Fe}^{\mathrm{II}}$ species from the resting state. Therefore, the CYP system can work efficiently without CYP-CPR or Cyt. $b_{5}-\mathrm{CPR}$ complexations. Very importantly, the electron relay sponsored by small diffusible species also explains the promiscuity of CPR and its low distribution densities within the microsomal membranes. In terms of reaction kinetics, the diffusible species mediated reduction of heme-Fe (quite similar to dithionite reduction) also overcomes the limitations of low CYP-CPR collision frequencies expected within the phospholipid membrane and obviates the need for lowprobability events of serial/sequential multi-molecular complexations (NADPH + CPR + Cyt. $b_{5}$, Cyt. $b_{5}+\mathrm{CYP}+$ substrate + oxygen; etc.), as sought by the classical model. The structural features of CYPs do not display any deterministic mandates that would be expected for a high fidelity binding with CPR, particularly given the reality that the latter protein is available at much lower concentrations and relative ratios. As shown in Figure 3, the CYPs show the conservation of an evolutionary mandate (freely solvent-accessible cysteine) to enable facile non-specific electron transfer dynamics, and support the murburn model of mXM. 


\section{How is the versatility and catalytic efficiency of the most prolific drug metabolizing enzyme, CYP3A4 explained?}

Experts in the field consider that the large distal pocket of CYP3A4 enables it the ability to accommodate drug molecules within the distal heme pocket site. If that were the case, even CYPs 2C9 and 2D6 have large distal pockets $\left(\sim 1500 \AA^{3}\right)$, but they are not as metabolically versatile as CYP3A4. We reason this is because CYP3A4 has multiple DROS-channels from the distal heme pocket connecting to periphery and substrate binding pockets on various suitable surface loci on the enzyme, which enable better stochastic/statistical presentation/interaction of the drug molecules. Analysis of the topography and cavities of CYP3A4 is presented in Figure S3 (and Video 1a \& 1b, which also shows hydrophobic helices / patches) of Supplementary File, Item 3. In particular, we would like to discuss CYP3A4's interaction with two moleculesclotrimazole and trabectedin (as shown in Figure 4 and Video 1b of Supplementary File S3), to demonstrate the murburn mechanistic perspective. Clotrimazole is a potent and acknowledged inhibitor of CYP3A4 activity (Turan, Mishin, and Thomas 2001). In the top panel, it can be clearly seen that clotrimazole can be docked within the distal active site, but it is highly unlikely that the molecule could access the heme center in physiological conditions, as the aperture of the channel to the distal cavity is too narrow. Also, there is no way that the central $\left(s p^{3}\right)$ tetra-ring substituted carbon atom (the moiety which is slowly reacted within the same enzyme reaction milieu) could be attacked by any heme Fe-O species. Therefore, it is not by binding at the distal heme pocket that CYP3A4 gets inhibited by clotrimazole. The top-right panel shows that when blind-docked, clotrimazole binds the proximal cavity on CYP3A4 efficiently $-6.48 \mathrm{kcal} / \mathrm{mol}$, thereby preventing heme reduction and thus, inhibiting global CYP3A4 activity with most of its substrates. Trabectedin is too large a molecule and cannot fit into the CYP3A4 distal pocket with a favorable energy term. However, the bottom panel of Figure 4 shows that it finds good docking sites on the surface, where it can conveniently access a DROS emerging from the distal site and thus gets metabolized effectively by the enzyme. Therefore, the preference and selectivity of substrates and inhibitors cannot be explained by a mere binding at the heme distal pocket, and murburn model allows a decentralization of the reaction centers to various loci within the system, to explain for the observed outcomes.

\section{Explaining the activity of CYP2C9 towards NSAIDS and warfarin}


A visual survey of the topography and cavities of CYP2C9 is presented in Figure S4 (and Video 2, which also shows hydrophobic helices) of Supplementary File, Item 3. Conventionally, the specificity of CYP2C9 hydroxylations of non-steroidal anti-inflammatory drugs, NSAIDS (at 4'OH for both flurbiprofen and diclofenac) and substrate selection of S-warfarin over R-warfarin (Wadelius et al. 2004) enantiomer were explained with distal heme pocket binding. A careful study of literature shows that the NSAID molecules also get hydroxylated at other loci (Manoj et al., 2016d) and the hydroxylation of warfarin is not enantioselective (that is- the product is a racemic hydroxylated mixture) (Rulcova et al. 2010). This lack of enantioselectivity in hydroxylation of a preferentially bound enantiomeric substrate cannot be explained in reaction outcomes if the binding at the distal pocket was directly translated to reaction at the hemeFecenter. In Figure 5, we show that flurbiprofen can bind at several loci near the channel and therefore, can avail the DROS species as it comes out. The possibility of DROS reacting at a particular locus is more a consequence of the energy terms involved in abstracting a proton and stabilization of the radical that results thereafter. Similarly, the preferential substrate of Swarfarin is seen and known to bind too far from the distal heme-Fe of CYP2C9 (Figure 5, right panel). Moreover, R-warfarin is found to bind better and is metabolized to the corresponding racemic alcohols even by the human cytosolic reductases (Barnette et al. 2017), which is yet again suggestive of involvement of DROS. Therefore, a mere preferential binding of an enantiomer cannot be seen as support for the classical view but in the light of the principle of parsimony, the overall outcomes should be taken as evidence for murburn mechanism.

\section{Explaining the CYP2D6 mediated enantioselective hydroxylation of bufuralol}

Bufuralol is one of the classical substrates of CYP2D6 and shows enantioselective hydroxylation at the benzylic carbon (Narimatsu et al. 2003). The topography and cavities of CYP2D6 is presented in Figure S5 (and Video 3 shows the easily accessible active site, and also shows hydrophobic helices) of Supplementary File, Item 3. Since the heme floor and its sides are confined spaces, we would expect enantioslective hydroxylations in suitable molecules that present enantiotopic faces differently. (Else, enantioselectivity can also be noted in the murburn

scheme if the substrate bound strongly at a given locus that happens to present the DROS in very predictable fashion.) If we assume that the Fe-O species is more stable than the probability of access of drug molecules' access to hemeFe, we can reason the enantioselectivity observed in 
benzylic hydroxylation of the activated carbon of bufuralol. Figure 6 shows a straight channel with wide aperture leading to the distal heme pocket and bufuralol docked at heme-center within bonding distance of hemeFe center. Since the molecule of bufuralol would not face kinetic restraints from the relatively large CYP2D6 channel, the access to hemeFe is not a limiting factor in this reaction and therefore, hydroxylation is stereoselective.

\section{Why is CYP2E1 so different?}

CYP2E1 reactions are known to produce more DROS, obligatorily need cytochrome $b_{5}$, react with halofluorocarbons and relatively more polar substrates via both oxidative and reductive pathways (White and Matteis 2001). The topography and cavities of CYP2E1 is presented in Figure S6 (and Video 4, which also depicts hydrophobic helices) of Supplementary File, Item 3. In Figure 7, it is shown that the heme distal pocket does not have connectivity to the distal surface and the proximal cysteine ligand side allows access to heme. Further, the proximal side serves as a relatively large cavity, which could be useful for binding various types of molecules with low affinity. It is known that CYP2E1 has a high percentage of hemeFe in high spin state. Therefore, the ROS production in this system would be high. The small distal pocket is merely for oxygen-superoxide and $\mathrm{Fe}-\mathrm{O}_{2}$ equilibrium dynamics, and not for substrate binding. Therefore, this enzyme is quite similar to the soluble P450cam system, which needs the generic redox capacitor of putidaredoxin, quite like CYP2E1 needs cyt. $b_{5}$.

\section{Explaining mutation studies and mechanism-based inactivations}

Paul Hollenberg's group has shown clopidogrel mediated mechanism-based inhibition of CYP2B6 by binding at C475 residue (Zhang et al. 2011) of CYP2B6. C475 is located on the distal surface of the protein, marked out in green within Figure 8. Demonstrating a $K_{d}$ value of $500 \mu \mathrm{M}$, clopidogrel seems to show low-affinity binding at C475. A mutation replacing C475 with serine inactivates the inhibitory effects, due to failed binding of clopidogrel at the site (Zhang et al. 2011). Such inhibitions are difficult to be explained via classical theories, but murburn embraces them quite easily. The most potent and mechanistically important probe of CYPs is perhaps 1-aminobenzotriazole (ABT), a potent mechanism-based inactivator (Montellano 2018). We have repeatedly argued that the physiological and routine enzyme assay conditions, at $\mathrm{nM}$ levels of enzymes and micromolar levels of small molecules/ligands, the 
probability of heme-distal access of the small molecule is kinetically challenged. Quite contrastingly, the classical oxygen-rebound mechanism mediated by Compound I seeks a highaffinity binding at heme center and protein conformation changes to explain reactivity. The ABT probe provides conclusive support for the relevance of murburn model within mXM. The relevant concepts are shown in Figure 9. ABT reacts with CYPs to give benzyne, which destroys the heme in CYP3A4, but the loss is relatively lesser in CYP2C9 and practically nil in CYP2E1 (although activity loss is obtained in CYP2E1 too!) (Montellano 2018). Pocket analysis of the crystal structures show that while the pyrrole nitrogens are accessible for benzyne's reaction within CYP3A4 distal pocket, it is restricted in CYP2C9. Since there is no large enough proximal channel connecting the small distal cavity of CYP2E1 to the distal side, ABT or benzyne cannot access the hemeFe. This reality agrees well with murburn mechanism which professes that the probability of diffusible reactive intermediate formation and release at hemecenter is greater than the substrate access to hemeFe. So, the electron-rich ABT can react with diffusible radicals in or outside the heme pocket, generating a freely diffusible radical species and benzyne thereafter. These entities can effectively compete with other substrate molecules and also destroy the heme of CYPs (save isozymes like CYP2E1). If the enzyme abided by classical mechanisms, the ABT substrate should have been hydroxylated by oxygen rebound (to give an $\mathrm{N}-\mathrm{OH}$ species) and voided from the active site thereafter. Further, it was experimentally observed that for every CYP lost, 12 molecules of ABT were consumed, which ratifies the murburn theory yet again- the probability of diffusible radical reacting with even a small molecule like ABT (as a substrate, in or out of the heme distal pocket) is much higher than the $\mathrm{N}$-atom's accessibility to hemeFe.

\section{Conclusions}

We advocate that only at high absolute concentrations of components and high ligand:enzyme ratios, the heme-distal active site could be occupied by small Type I \& II binders; and classical purviews may not be applicable to the physiological flux dynamics involving several drugs/xenobiotics. We don't negate the experimental evidence provided by X-ray crystallography or spectroscopy. But we caution that these are obtained at very high concentrations of the protein and ligand, which are not usually relevant in physiology. Therefore, hemeFe is most likely to recycle via $\mathrm{Fe}^{2+}-\mathrm{Fe}^{3+}$ cycles and not go to Compound I type states. 
Compound $\mathrm{I}$ is formed in peroxidases and requires a heterolytic scission of peroxide at the heme center, which is aided by polar active site residues. Such facets are missing in liver microsomal CYPs altogether. The distal pocket enhances the lifetime of the superoxide or hydroxyl radicals and it is not primarily meant for binding substrates. If it was, we should have observed larger channels to the cavity. There is no known machinery for CYPs to activate their F and G loops to open up only for specific molecules. The murburn interpretation does justice to the crystal structures of proteins and their complexes with small molecules. Unlike the diatomic oxygen/superoxide/hydroxyl species that can diffuse and squeeze through small spaces and reach obstructed sites, the large molecules have serious limitations. Similarly, the scope of formation and relevance of reactions of Compound I are also limited to very few cases. The overall reaction paradigm is a delocalized and stochastic interaction scheme of DROS, one-electron reactive intermediates and various equilibriums between these species in a highly dynamic milieu. Our projections and calculations are evidenced by the fact that CYPs taken in conjunction with stabilized superoxide can give the specific reaction products, without $\mathrm{NAD}(\mathrm{P}) \mathrm{H}$ or CPR or Cyt. b5 (Kelath Murali Manoj, Parashar, Gade, et al. 2016; Parashar, Gideon, and Manoj 2018). This invokes the simple deduction that physiological system is a modality for efficient generation and utilization of DROS.

These mechanistic findings have tremendous impact on the trillion dollar drug industry (Table 1). From a deterministic view of CYP reactions, we need to move on to a more complex stochastic interactive system, to understand the physiological relevance. Standard kinetic constants, active site based interpretations for inhibitions, watching out to minimize DROS productions, etc. can no longer be considered as deterministic yardsticks for pharmacokinetic research. Under the light of murburn concept, we need to understand drug-drug interactions and the mandate for personal medicine (idiosyncratic and hormetic dose responses) with a fresh perspective.

Declarations: The work was powered by Satyamjayatu: The Science \& Ethics Foundation. The authors have no conflict of interests to declare.

\section{References}


Andrew, D, L Hager, and K M Manoj. 2011. "The Intriguing Enhancement of Chloroperoxidase Mediated One-Electron Oxidations by Azide, a Known Active-Site Ligand.” Biochemical and Biophysical Research Communications 414: 646-49.

Barnette, Dustyn A., Bryce P. Johnson, Dakota L. Pouncey, Robert Nshimiyimana, Linda P. Desrochers, Thomas E. Goodwin, and Grover P. Miller. 2017. "Stereospecific Metabolism of R- and S-Warfarin by Human Hepatic Cytosolic Reductases.” Drug Metabolism and Disposition 45 (9): 1000-1007. https://doi.org/10.1124/dmd.117.075929.

Bazhin, N. M. 2020. "Standard and Transformed Values of Gibbs Energy Formation for Some Radicals and Ions Involved in Biochemical Reactions." Archives of Biochemistry and Biophysics 686. https://doi.org/10.1016/j.abb.2020.108282.

Cryle, Max J., Nick J. Matovic, and James J. De Voss. "The stereochemistry of fatty acid hydroxylation by cytochrome P450BM3." Tetrahedron Letters 48, no. 1 (2007): 133-136.

DeLano, W L. 2002. “The PyMOL Molecular Graphics System. DeLano Scientific; San Carlos, CA, USA.” 2002. http://www.pymol.org.

DeVore, N M, K M Meneely, A G Bart, E S Stephens, K P Battaile, and E E Scott. 2012. "Structural Comparison of Cytochromes P450 2A6, 2A13, and 2E1 with Pilocarpine." FEBS Journal 279 (9): 1621-31. https://doi.org/10.1111/j.1742-4658.2011.08412.x.

Gade, S K, S Bhattacharya, and K M Manoj. 2012. "Redox Active Molecules Cytochrome c and Vitamin C Enhance Heme-Enzyme Peroxidations by Serving as Non-Specific Agents for Redox Relay." Biochemical and Biophysical Research Communications 419: 211-14.

Ghosh, D, J Lo, D Morton, D Valette, J Xi, J Griswold, S Hubbell, et al. 2012. "Novel Aromatase Inhibitors by Structure-Guided Design.” Journal of Medicinal Chemistry 55 (19): 8464-76. https://doi.org/10.1021/jm300930n.

Honeychurch, Michael J., H. Allen O. Hill, and Luet-Lok Wong. "The thermodynamics and kinetics of electron transfer in the cytochrome P450cam enzyme system." FEBS letters 451, no. 3 (1999): 351-353.

Hsu, Mei Hui, and Eric F. Johnson. 2019. "Active-Site Differences between Substrate-Free and Ritonavir Bound Cytochrome P450 (CYP) 3A5 Reveal Plasticity Differences between CYP3A5 and CYP3A4.” Journal of Biological Chemistry 294 (20): 8015-22. https://doi.org/10.1074/jbc.RA119.007928.

Manoj, K M. 2006. "Chlorinations Catalyzed by Chloroperoxidase Occur via Diffusible Intermediate (s) and the Reaction Components Play Multiple Roles in the Overall Process." Biochimica et Biophysica Acta (BBA) - Proteins and Proteomics 1764 (8): 1325-39.

Manoj, K M, A Baburaj, B Ephraim, F Pappachan, P P Maviliparambathu, U K Vijayan, S V Narayanan, K Periasamy, E A George, and L T Mathew. 2010. "Explaining the Atypical Reaction Profiles of Heme Enzymes with a Novel Mechanistic Hypothesis and Kinetic Treatment." PloS One 5 (5): e10601.

Manoj, K M, S K Gade, and L Mathew. 2010. "Cytochrome P450 Reductase: A Harbinger of 
Diffusible Reduced Oxygen Species.” PloS One 5 (10): e13272.

Manoj, K M, and L P Hager. 2008. “Chloroperoxidase, a Janus Enzyme.” Biochemistry 47 (9): 2997-3003.

Manoj, Kelath Murali, and Nikolai Mikhailovich Bazhin. 2019. "Murburn Precepts of Aerobic Respiration.” OSF Preprints 8th Nov. https://doi.org/doi:10.31219/osf.io/hx4p9.

Manoj, Kelath Murali, Sudeep K Gade, Avanthika Venkatachalam, and Daniel A Gideon. 2016. "Electron Transfer amongst Flavo-and Hemo-Proteins: Diffusible Species Effect the Relay Processes, Not Protein-Protein Binding." RSC Advances 6 (29): 24121-29.

Manoj, Kelath Murali, Daniel Andrew Gideon, Abhinav Parashar, Deepak Haarith, and Afsal Manekkathodi. 2020. "Microsomal Xenobiotic Metabolism, Mitochondrial Oxidative Phosphorylation and Cyanobacterial Photorespiration Have Common Murburn Mechanistic Underpinnings with Chloroplastid Photosynthetic Physiology.” OSF Preprints July 9. https://doi.org/doi:10.31219/osf.io/8p2sx.

Manoj, Kelath Murali, and Lowell P Hager. 2001. "Utilization of Peroxide and Its Relevance in Oxygen Insertion Reactions Catalyzed by Chloroperoxidase." Biochimica et Biophysica Acta (BBA) - Protein Structure and Molecular Enzymology 1547 (2): 408-17.

Manoj, Kelath Murali, Abhinav Parashar, Vivian David Jacob, and Surjith Ramasamy. 2019. "Aerobic Respiration: Proof of Concept for the Oxygen-Centric Murburn Perspective." Journal of Biomolecular Structure and Dynamics, 1-15. https://doi.org/10.1080/07391102.2018.1552896.

Manoj, Kelath Murali, Abhinav Parashar, Sudeep K. Gade, and Avanthika Venkatachalam. 2016. "Functioning of Microsomal Cytochrome P450s: Murburn Concept Explains the Metabolism of Xenobiotics in Hepatocytes." Frontiers in Pharmacology 7 (JUN): 161. https://doi.org/10.3389/fphar.2016.00161.

Manoj, Kelath Murali, Abhinav Parashar, Avanthika Venkatachalam, Sahil Goyal, Satyalipsu, Preeti Gunjan Singh, Sudeep K. Gade, et al. 2016. "Atypical Profiles and Modulations of Heme-Enzymes Catalyzed Outcomes by Low Amounts of Diverse Additives Suggest Diffusible Radicals' Obligatory Involvement in Such Redox Reactions.” Biochimie 125: 91-111. https://doi.org/10.1016/j.biochi.2016.03.003.

Manoj, Kelath Murali, Surjith Ramasamy, Abhinav Parashar, Daniel Andrew Gideon, Vidhu Soman, Vivian David Jacob, and Kannan Pakshirajan. 2020. "Acute Toxicity of Cyanide in Aerobic Respiration: Theoretical and Experimental Support for Murburn Explanation.” Biomolecular Concepts 11 (1): 32-56. https://doi.org/10.1515/bmc-2020-0004.

Manoj, Kelath Murali, and Vidhu Soman. 2020. "Classical and Murburn Explanations for Acute Toxicity of Cyanide in Aerobic Respiration: A Personal Perspective.” Toxicology 432: 152369. https://doi.org/10.1016/j.tox.2020.152369.

Manoj, Kelath Murali, Vidhu Soman, Vivian David Jacob, Abhinav Parashar, Daniel Andrew Gideon, Manish Kumar, Afsal Manekkathodi, Surjith Ramasamy, Kannan Pakshirajan, and 
Nikolai Mikhailovich Bazhin. 2019. "Chemiosmotic and Murburn Explanations for Aerobic Respiration: Predictive Capabilities, Structure-Function Correlations and Chemico-Physical Logic." Archives of Biochemistry and Biophysics 676: 108128.

https://doi.org/10.1016/j.abb.2019.108128.

Manoj, Kelath Murali, Avanthika Venkatachalam, and Abhinav Parashar. 2016. "Metabolism of Xenobiotics by Cytochrome P450: Novel Insights into the Thermodynamics, Kinetics and Roles of Redox Proteins and Diffusible Reactive Species." In Drug Metabolism Reviews, 48:41-42. Taylor \& Francis Ltd 2-4 Park Square, Milton Park, Abingdon Or14 4rn, Oxon, England.

Montellano, Paul R.Ortiz de. 2015. Cytochrome P450: Structure, Mechanism, and Biochemistry, Fourth Edition. Cytochrome P450: Structure, Mechanism, and Biochemistry, Fourth Edition. https://doi.org/10.1007/978-3-319-12108-6.

Montellano, Paul R Ortiz de. 2018. "1-Aminobenzotriazole: A Mechanism-Based Cytochrome P450 Inhibitor and Probe of Cytochrome P450 Biology.” Medicinal Chemistry 08 (03). https://doi.org/10.4172/2161-0444.1000495.

Morris, Garrett M, Ruth Huey, William Lindstrom, Michel F Sanner, Richard K Belew, David S Goodsell, and Arthur J Olson. 2009. "AutoDock4 and AutoDockTools4: Automated Docking with Selective Receptor Flexibility." Journal of Computational Chemistry 30 (16): 2785-91.

Narimatsu, Shizuo, Chie Takemi, Shino Kuramoto, Daisuke Tsuzuki, Hiroyuki Hichiya, Keietsu Tamagake, and Shigeo Yamamoto. 2003. "Stereoselectivity in the Oxidation of Bufuralol, a Chiral Substrate, by Human Cytochrome P450s." Chirality 15 (4): 333-39. https://doi.org/10.1002/chir.10212.

O’Boyle, Noel M, Michael Banck, Craig A James, Chris Morley, Tim Vandermeersch, and Geoffrey R Hutchison. 2011. "Open Babel: An Open Chemical Toolbox." Journal of Cheminformatics 3 (1): 1-14.

Parashar, Abhinav, Sudeep Kumar Gade, Mahesh Potnuru, Nandita Madhavan, and Kelath Murali Manoj. 2014. "The Curious Case of Benzbromarone: Insight into Super-Inhibition of Cytochrome P450.” PLoS ONE 9 (3). https://doi.org/10.1371/journal.pone.0089967.

Parashar, Abhinav, Daniel Andrew Gideon, and Kelath Murali Manoj. 2018. "Murburn Concept: A Molecular Explanation for Hormetic and Idiosyncratic Dose Responses." Dose-Response 16 (2): 1559325818774421. https://doi.org/10.1177/1559325818774421.

Parashar, Abhinav, and Kelath Murali Manoj. 2012. "Traces of Certain Drug Molecules Can Enhance Heme-Enzyme Catalytic Outcomes." Biochemical and Biophysical Research Communications 417 (3): 1041-45. https://doi.org/10.1016/j.bbrc.2011.12.090.

Parashar, Abhinav, Avanthika Venkatachalam, Daniel Andrew Gideon, and Kelath Murali Manoj. 2014. "Cyanide Does More to Inhibit Heme Enzymes, than Merely Serving as an Active-Site Ligand.” Biochemical and Biophysical Research Communications 455 (3-4): 190-93. https://doi.org/10.1016/j.bbrc.2014.10.137. 
Pettersen, Eric F, Thomas D Goddard, Conrad C Huang, Gregory S Couch, Daniel M Greenblatt, Elaine C Meng, and Thomas E Ferrin. 2004. "UCSF Chimera-a Visualization System for Exploratory Research and Analysis." Journal of Computational Chemistry 25 (13): 160512.

Porubsky, Patrick R., Kathleen M. Meneely, and Emily E. Scott. 2008. "Structures of Human Cytochrome P-450 2E1: Insights into the Binding of Inhibitors and Both Small Molecular Weight and Fatty Acid Substrates." Journal of Biological Chemistry 283 (48): 33698-707. https://doi.org/10.1074/jbc.M805999200.

Poulos, Thomas L, Barry C Finzel, and Andrew J Howard. 1987. "High-Resolution Crystal Structure of Cytochrome P450cam.” Journal of Molecular Biology 195 (3): 687-700. https://doi.org/10.1016/0022-2836(87)90190-2.

Reynald, R L, S Sansen, C D Stout, and E F Johnson. 2012. "Structural Characterization of Human Cytochrome P450 2C19: Active Site Differences between P450s 2C8, 2C9, and 2C19." Journal of Biological Chemistry 287 (53): 44581-91. https://doi.org/10.1074/jbc.M112.424895.

Rulcova, A., I. Prokopova, L. Krausova, M. Bitman, R. Vrzal, Z. Dvorak, J. Blahos, and P. Pavek. 2010. "Stereoselective Interactions of Warfarin Enantiomers with the Pregnane X Nuclear Receptor in Gene Regulation of Major Drug-Metabolizing Cytochrome P450 Enzymes." Journal of Thrombosis and Haemostasis 8 (12): 2708-17. https://doi.org/10.1111/j.1538-7836.2010.04036.x.

Sansen, S, J K Yano, R L Reynald, G A Schoch, K J Griffin, C D Stout, and E F Johnson. 2007. "Adaptations for the Oxidation of Polycyclic Aromatic Hydrocarbons Exhibited by the Structure of Human P450 1A2." Journal of Biological Chemistry 282 (19): 14348-55. https://doi.org/10.1074/jbc.M611692200.

Schoch, G A, J K Yano, M R Wester, K J Griffin, C D Stout, and E F Johnson. 2004. "Structure of Human Microsomal Cytochrome P450 2C8. Evidence for a Peripheral Fatty Acid Binding Site." Journal of Biological Chemistry 279 (10): 9497-9503. https://doi.org/10.1074/jbc.M312516200.

Sevrioukova, Irina F., Huiying Li, Hong Zhang, Julian A. Peterson, and Thomas L. Poulos. "Structure of a cytochrome P450-redox partner electron-transfer complex." Proceedings of the National Academy of Sciences 96, no. 5 (1999): 1863-1868.

Sevrioukova, Irina F., and Thomas L. Poulos. 2010. "Structure and Mechanism of the Complex between Cytochrome P4503A4 and Ritonavir." Proceedings of the National Academy of Sciences of the United States of America 107 (43): 18422-27. https://doi.org/10.1073/pnas.1010693107.

Sevrioukova, Irina F., Thomas L. Poulos, and Inna Y. Churbanova. 2010. "Crystal Structure of the Putidaredoxin Reductase·putidaredoxin Electron Transfer Complex." Journal of Biological Chemistry 285 (18): 13616-20. https://doi.org/10.1074/jbc.M110.104968.

Shah, Manish B., P. Ross Wilderman, Jingbao Liu, Hyun Hee Jang, Qinghai Zhang, C. David 
Stout, and James R. Halpert. 2015. "Structural and Biophysical Characterization of Human Cytochromes P450 2B6 and 2A6 Bound to Volatile Hydrocarbons: Analysis and Comparison." Molecular Pharmacology 87 (4): 649-59.

https://doi.org/10.1124/mol.114.097014.

Strushkevich, N V, W Tempel, A A Gilep, P Loppnau, C H Arrowsmith, A M Edwards, C Bountra, M Wilkstrom, A Bochkarev, and H Park. 2008. "Crystal Structure of CYP2R1 in Complex with Vitamin D2.” https://doi.org/10.2210/pdb3czh/pdb.

Sundaramoorthy, Munirathinam, James Terner, and Thomas L Poulos. 1995. "The Crystal Structure of Chloroperoxidase: A Heme Peroxidase-Cytochrome P450 Functional Hybrid." Structure 3 (12): 1367-78.

Tian, Wei, Chang Chen, Xue Lei, Jieling Zhao, and Jie Liang. 2018. "CASTp 3.0: Computed Atlas of Surface Topography of Proteins." Nucleic Acids Research 46: W363-67. https://doi.org/10.1093/nar/gky473.

Tripathi, Sarvind, Huiying Li, and Thomas L. Poulos. 2013. "Structural Basis for Effector Control and Redox Partner Recognition in Cytochrome P450." Science 340 (6137): 122730. https://doi.org/10.1126/science.1235797.

Turan, Valerie K., Vladimir M. Mishin, and Paul E. Thomas. 2001. "Clotrimazole Is a Selective and Potent Inhibitor of Rat Cytochrome P450 3A Subfamily-Related Testosterone Metabolism." Drug Metabolism and Disposition 29 (6): 837-42.

Venkatachalam, Avanthika, Abhinav Parashar, and Kelath Murali Manoj. 2016. "Functioning of Drug-Metabolizing Microsomal Cytochrome P450s: In Silico Probing of Proteins Suggests That the Distal Heme 'Active Site' Pocket Plays a Relatively 'Passive Role' in Some Enzyme-Substrate Interactions." In Silico Pharmacology 4 (1): 1. https://doi.org/10.1186/s40203-016-0016-7.

Wadelius, Mia, K. Sörlin, O. Wallerman, J. Karlsson, Q. Y. Yue, P. K.E. Magnusson, C. Wadelius, and H. Melhus. 2004. "Warfarin Sensitivity Related to CYP2C9, CYP3A5, ABCB1 (MDR1) and Other Factors." Pharmacogenomics Journal 4 (1): 40-48. https://doi.org/10.1038/sj.tpj.6500220.

Walsh, A A, G D Szklarz, and E E Scott. 2013. "Human Cytochrome P450 1A1 Structure and Utility in Understanding Drug and Xenobiotic Metabolism." Journal of Biological Chemistry 288 (18): 12932-43. https://doi.org/10.1074/jbc.M113.452953.

Wang, A, U Savas, C D Stout, and E F Johnson. 2011. "Structural Characterization of the Complex between Alpha-Naphthoflavone and Human Cytochrome P450 1B1." Journal of Biological Chemistry 286 (7): 5736-43. https://doi.org/10.1074/jbc.M110.204420.

Wang, An, C. David Stout, Qinghai Zhang, and Eric F. Johnson. 2015. "Contributions of Ionic Interactions and Protein Dynamics to Cytochrome P450 2D6 (CYP2D6) Substrate and Inhibitor Binding." Journal of Biological Chemistry 290 (8): 5092-5104. https://doi.org/10.1074/jbc.M114.627661. 
Wester, Michael R, Jason K Yano, Guillaume A Schoch, Christine Yang, Keith J Griffin, C David Stout, and Eric F Johnson. 2004. "The Structure of Human Cytochrome P450 2C9 Complexed with Flurbiprofen at 2.0-Å Resolution.” Journal of Biological Chemistry 279 (34): $35630-37$.

White, Ian N.H., and Francesco De Matteis. 2001. "The Role of CYP Forms in the Metabolism and Metabolic Activation of HCFCs and Other Halocarbons." Toxicology Letters 124 (1-3): 121-28. https://doi.org/10.1016/S0378-4274(00)00288-5.

Williams, Pamela A, Jose Cosme, Alison Ward, Hayley C Angove, Vinkovi, Dijana Matak cacute, and Harren Jhoti. 2003. "Crystal Structure of Human Cytochrome P450 2C9 with Bound Warfarin.” Nature 424 (6947): 464-68.

Yano, J K, M R Wester, G A Schoch, K J Griffin, C D Stout, and E F Johnson. 2004. "The Structure of Human Microsomal Cytochrome P450 3A4 Determined by X-Ray Crystallography to 2.05-A Resolution." Journal of Biological Chemistry 279 (37): 3809194. https://doi.org/10.1074/jbc.C400293200.

Yano, Jason K., Travis T. Denton, Matthew A. Cerny, Xiaodong Zhang, Eric F. Johnson, and John R. Cashman. 2006. "Synthetic Inhibitors of Cytochrome P-450 2A6: Inhibitory Activity, Difference Spectra, Mechanism of Inhibition, and Protein Cocrystallization." Journal of Medicinal Chemistry 49 (24): 6987-7001. https://doi.org/10.1021/jm060519r.

Yu, Jian, Yong Zhou, Isao Tanaka, and Min Yao. 2010. "Roll: A New Algorithm for the Detection of Protein Pockets and Cavities with a Rolling Probe Sphere." Bioinformatics 26 (1): 46-52. https://doi.org/10.1093/bioinformatics/btp599.

Zhang, Haoming, Hemali Amunugama, Sarah Ney, Nyemade Cooper, and Paul F. Hollenberg. 2011. "Mechanism-Based Inactivation of Human Cytochrome P450 2B6 by Clopidogrel: Involvement of Both Covalent Modification of Cysteinyl Residue 475 and Loss of Heme." Molecular Pharmacology 80 (5): 839-47. https://doi.org/10.1124/mol.111.073783.

\section{Table, Figures and Legends}


Table 1: Changes in perceptions regarding the mXM system

\begin{tabular}{|c|c|c|c|}
\hline No. & Criterion/Explanation & P450cam model & Murburn model \\
\hline \multicolumn{4}{|c|}{ Mechanistic perceptions } \\
\hline 1 & Role of DROS & Toxic wastes & Reaction mainstay \\
\hline 2 & Locus of oxygen activation & $\begin{array}{l}\text { At heme-Fe, after CYP binds } \\
\text { substrate and is reduced by } \\
\text { CPR complexation }\end{array}$ & $\begin{array}{l}\text { At flavin of CPR; high spin heme can } \\
\text { generate singlet oxygen, enhancing } \\
\text { rate }\end{array}$ \\
\hline 3 & $\begin{array}{l}\text { Reason for substrate diversity } \\
\text { and/or preference }\end{array}$ & $\begin{array}{l}\text { Opening of } F \& G \text { loops } \\
\text { leading to high affinity binding } \\
\text { at the bulbous distal heme } \\
\text { pocket }\end{array}$ & $\begin{array}{l}\text { Substrates binds anywhere- in, on or } \\
\text { around the CYP }\end{array}$ \\
\hline 4 & $\begin{array}{l}\text { Mechanism of oxygen insertion } \\
\text { into the substrate (role of heme } \\
\text { distal pocket) }\end{array}$ & $\begin{array}{l}\text { 2e oxygen rebound at heme-Fe } \\
\text { at Compound I (distal pocket } \\
\text { binds the substrates) }\end{array}$ & $\begin{array}{l}\text { 1e process in/on/around the CYP; } 2 \mathrm{e} \\
\text { mechanism possible with small } \\
\text { substrates at an high } \\
\text { concentrations/ratios of components } \\
\text { (distal pocket stabilizes DROS at } \\
\text { heme-Fe) }\end{array}$ \\
\hline 5 & $\begin{array}{l}\text { Locus and reason for loss of } \\
\text { NADPH by water formation }\end{array}$ & Oxidase shunt at Compound I & Reactions between DROS in milieu \\
\hline 6 & $\begin{array}{l}\text { Locus/source of } \\
\text { formation }\end{array}$ & $\begin{array}{l}\text { Ineffective substrate binding at } \\
\text { heme-center }\end{array}$ & $\begin{array}{l}\text { Equilibrium driven, either at CPR or } \\
\text { heme-center or in milieu reactions }\end{array}$ \\
\hline 7 & Stoichiometry & Deterministic and integral & Variable and non-integral \\
\hline 8 & $\begin{array}{l}\text { Electron transfers (CPR's } \\
\text { promiscuity) }\end{array}$ & $\begin{array}{l}\text { Long range electron transfer } \\
\text { between CPR-Cyt. b5 and Cyt. } \\
\text { b5-CYP }\end{array}$ & $\begin{array}{l}\text { Non-specific redox buffers and relays } \\
\text { by DROS and ions }\end{array}$ \\
\hline 9 & Role of Cyt. $b_{5}$ & $\begin{array}{l}\text { Electron shuttler or complexer } \\
\text { between CPR and CYP }\end{array}$ & $\begin{array}{l}\text { Acts as a redox capacitor absorbing } \\
\text { and releasing } 1 \mathrm{e}\end{array}$ \\
\hline 10 & Lipid membrane & $\begin{array}{l}\text { Aids co-localization and } \\
\text { complexing of CYP-Cyt. b5- } \\
\text { CPR }\end{array}$ & $\begin{array}{l}\text { Aids co-localization and DROS } \\
\text { dynamics }\end{array}$ \\
\hline \multicolumn{4}{|c|}{ Applications in clinical research } \\
\hline 11 & $\begin{array}{l}\text { Atypical kinetics and substrate } \\
\text { inhibition; Kinetic constants } \\
\left(K_{\mathrm{M}}, \mathbf{I C}_{50} \text { etc, } \mathbf{K}_{\mathrm{i}} \text {, etc.) }\right.\end{array}$ & $\begin{array}{l}\text { Active site or allosteric site } \\
\text { substrate binding/modulation; } \\
\text { Valuable characteristic of CYP- } \\
\text { substrate/inhibitor interaction }\end{array}$ & $\begin{array}{l}\text { Substrate interactions with reactive } \\
\text { intermediates formed; Not } \\
\text { theoretically accurate, as they reflect } \\
\text { DROS/CYP's interactions with } \\
\text { substrate/inhibitor }\end{array}$ \\
\hline 12 & $\begin{array}{l}\text { Drug-drug interaction } \\
\text { additive-based activations }\end{array}$ & $\begin{array}{l}\text { All outcomes at CYP active site } \\
\text { or allosteric modulation }\end{array}$ & $\begin{array}{l}\text { DROS-reactive intermediate-additive } \\
\text { interaction dynamics }\end{array}$ \\
\hline 13 & $\begin{array}{l}\text { Physiological roles of mutations } \\
\text { and importance of genotyping }\end{array}$ & Very significant & $\begin{array}{l}\text { Mutations could be significant, but } \\
\text { usually not }\end{array}$ \\
\hline 14 & $\begin{array}{l}\text { Liver health (fatty liver, } \\
\text { cirrhosis, glycogen deposit, etc.) }\end{array}$ & Not very significant & Highly important criterion \\
\hline 15 & Drug molecule optimization & Minimize DROS & $\begin{array}{l}\text { Depends on the reaction system, } \\
\text { molecule \& CYP }\end{array}$ \\
\hline
\end{tabular}




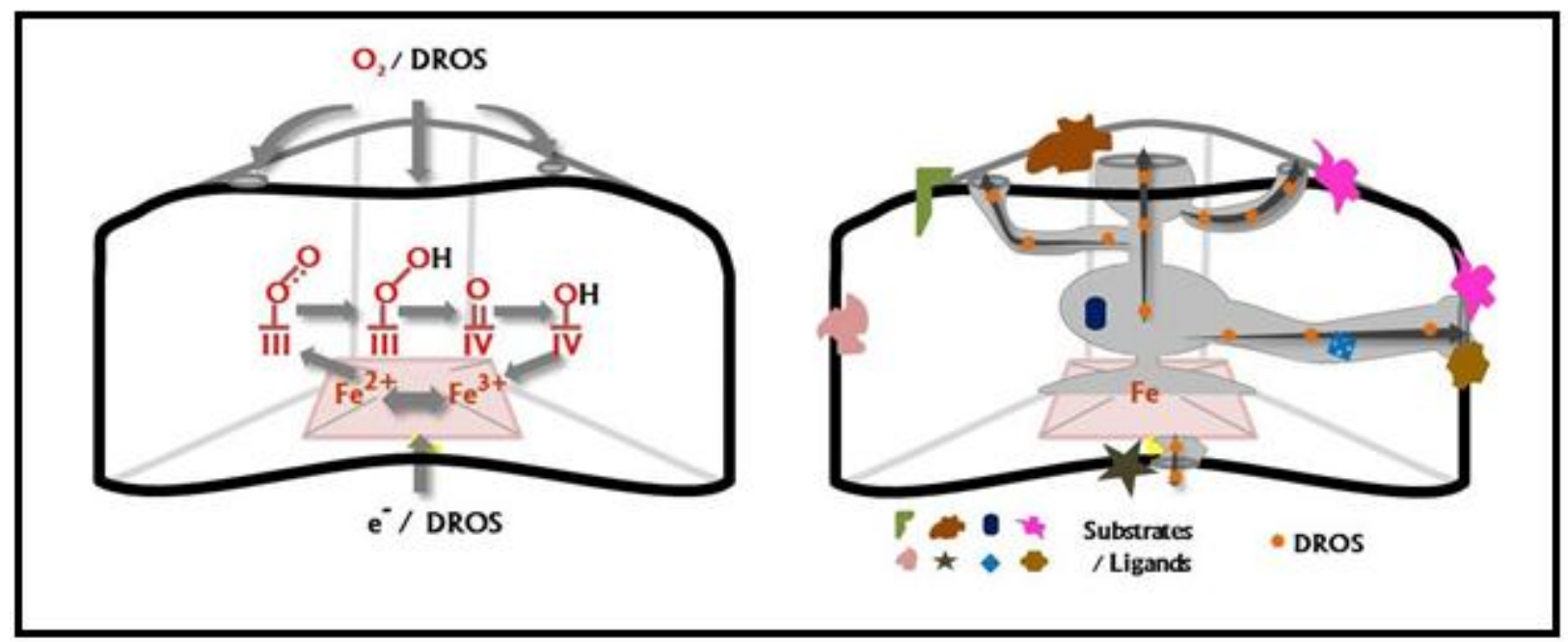

Figure 1: The murburn mechanistic purview supports the operational feasibility of multiple reactive species and substrate binding at various loci with liver microsomal CYP. The left panel shows that the solvent-accessible proximal cysteine could enable reduction of $\mathrm{Fe}^{3+}$ to $\mathrm{Fe}^{2+}$, which could allow oxygen-binding, giving a ferrous- $\mathrm{O}_{2}$ or ferric-superoxide species. This is also equivalent to superoxide accessing the distal pocket by its own merit. At the heme center, depending on the active site residues and DROS presented, a bevy of intermediates could be formed or released. The probability of substrate (bound with low affinity at various loci on the enzyme) interaction with DROS is thereby enhanced significantly. Since murzyme milieus work via stochastic/statistical modalities and involve competing reactions), they often show uncoupling, nonintegral and varying stoichiometry. 


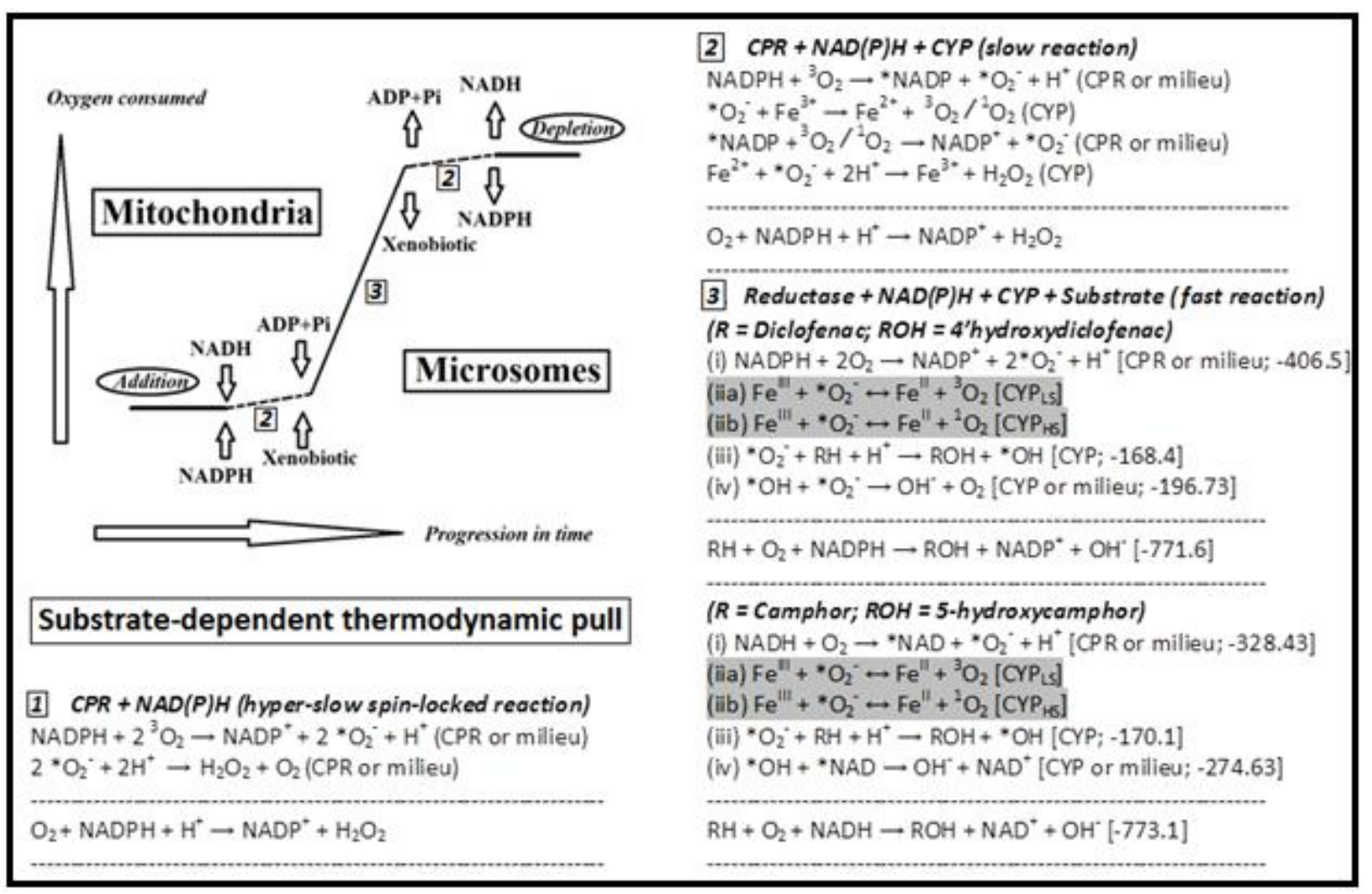

Figure 2: Experimental progress curves of mitochondrial aerobic respiration / microsomal xenobiotic metabolism and the pertinent minimalistic equations in mXM. At the initial time, addition of reduced nicotinamide nucleotide shows a very slow consumption of oxygen (depicted by dashed line, as explained in equations 2) and only the addition of substrate enables a higher reaction rate (shown in continuous line with high slope, intervening the two dashed lines, as explained by equation 3), which once again acquires the same rate of oxygen-consumption upon substrate depletion (the dashed line to the right top). In equation set 3 , we show minimalistic/typical reactions of the liver mcrosomal membrane-bound and soluble bacterial P450 reactions, exemplified by CYP2C9 (diclofenac, aromatic hydroxylation) and CYP101 (camphor, aliphatic hydroxylation). The values given in the right panel's braces are $\Delta_{\mathrm{r}} G^{\prime 0}{ }_{\text {aq }}$ [transformed Gibbs free energy, $\mathrm{kJ} / \mathrm{mol}$; values for the standard Gibbs free energy of formation of substrates and products for step (iii) were obtained from MetCyc]. 


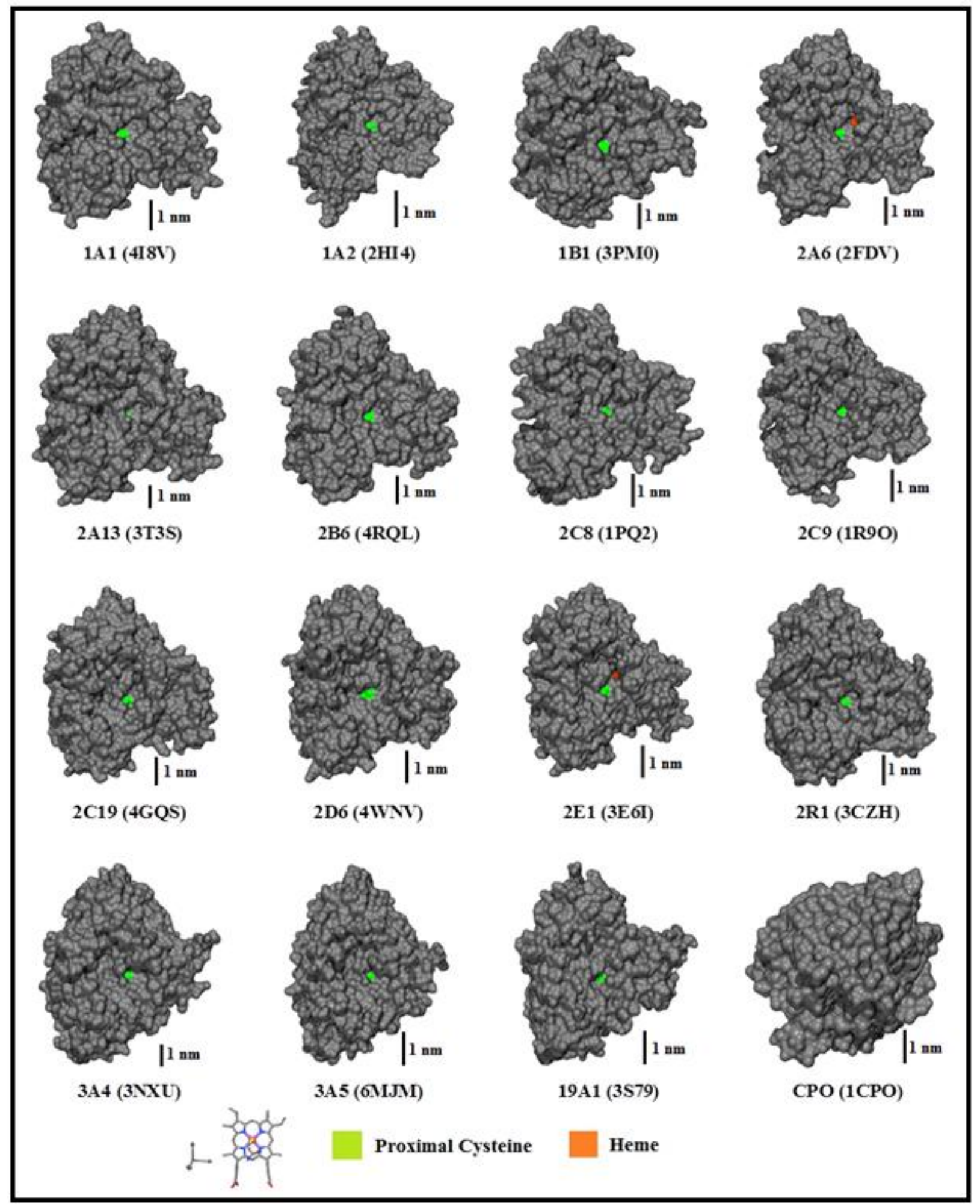

Figure 3: Proximal views of various mammalian CYPs and a comparison with chloroperoxidase. The solvent-accessible cysteine heme-Fe ligand of various mammalian CYPs is highlighted (bright green) is compared with chloroperoxidase, another heme-thiolate enzyme from the fungus $C$. fumago. 


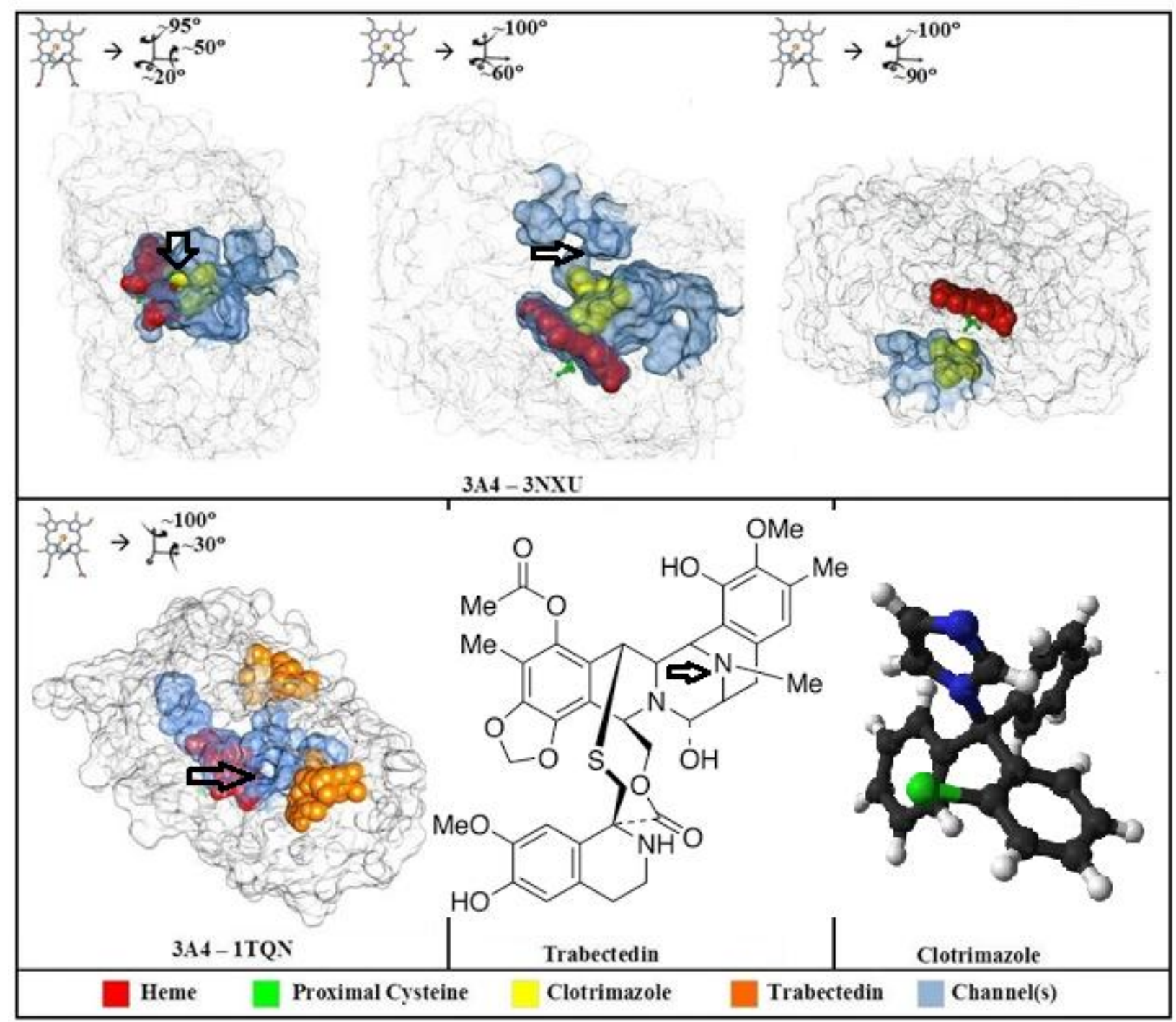

Figure 4: CYP3A4's interaction with clotrimazole and trabectedin: Clotrimazole is a relatively big molecule, but still can fit inside the bulbous cavity of CYP3A4. The challenge for clotrimazole although, would be to enter this cavity through the available orifices (one of the three is marked in the top-left) and even more to pass through the constricted region of the channel (marked in top-center). A facile site for binding is available on the proximal side (as shown in top-right). In bottom-left, two molecules of trabectedin are shown bound to the surface of CYP3A4, and it can be seen that a distal-cavity channel opens (duly marked) close to the hydrophobic patch where trabectedin is bound. A study of the molecular structure of the two compounds shows that their structures cannot permit a facile interaction of the reaction moiety with the confined ambiance of heme-center. 


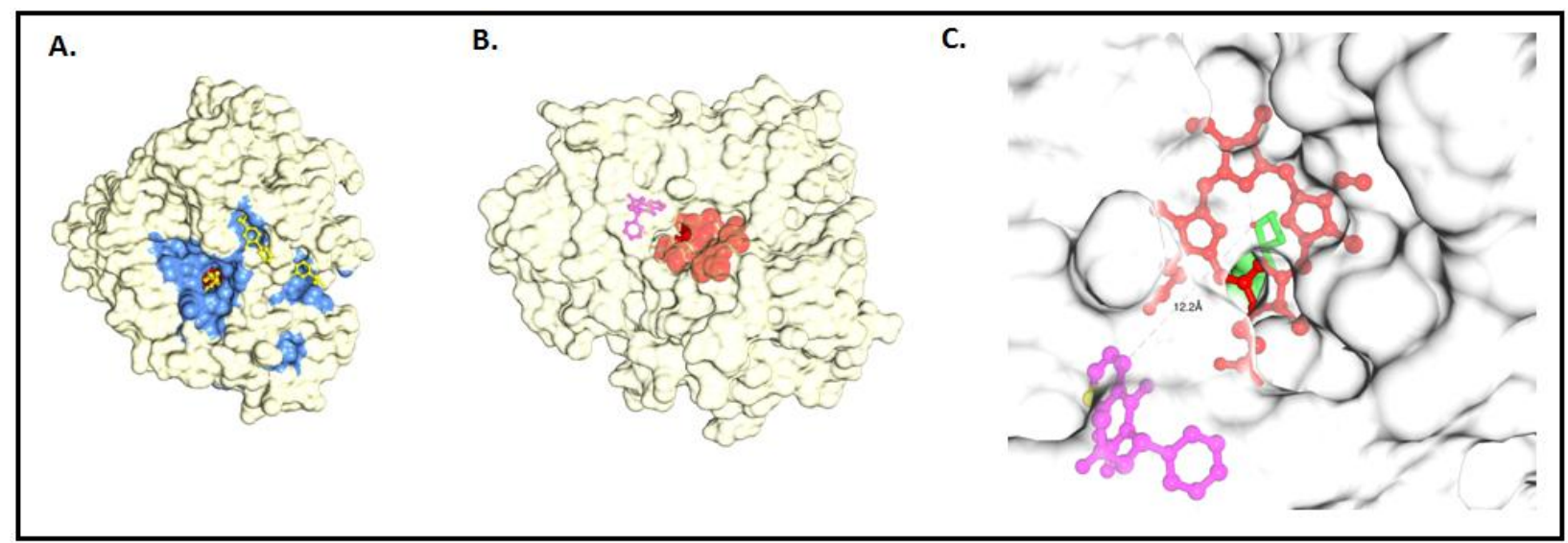

Figure 5: CYP2C9 (1R9O) binding with flurbiprofen and warfarin. The topography of CYP2C9 along with various binding sites for its substrate flurbiprofen are shown in panel A. The binding energy terms for the three sites are -7.35 (within the distal pocket, with the 4' carbon being $4.4 \AA$ A distant from hemeFe), -5.4 (within the channel accessing the distal cavity) and $-6.2 \mathrm{kcal} / \mathrm{mol}$ respectively. Taking into account the small orifice of the channel, a molecule like flurbiprofen would be kinetically constrained to reach the distal hemeFe and even reaching the distal pocket cannot afford it bonding proximity with a heme-Fe species. The panels B and C show that the channel accessing the heme is restrictive and that warfarin (blue) is bound too far from the hemeFe (red).

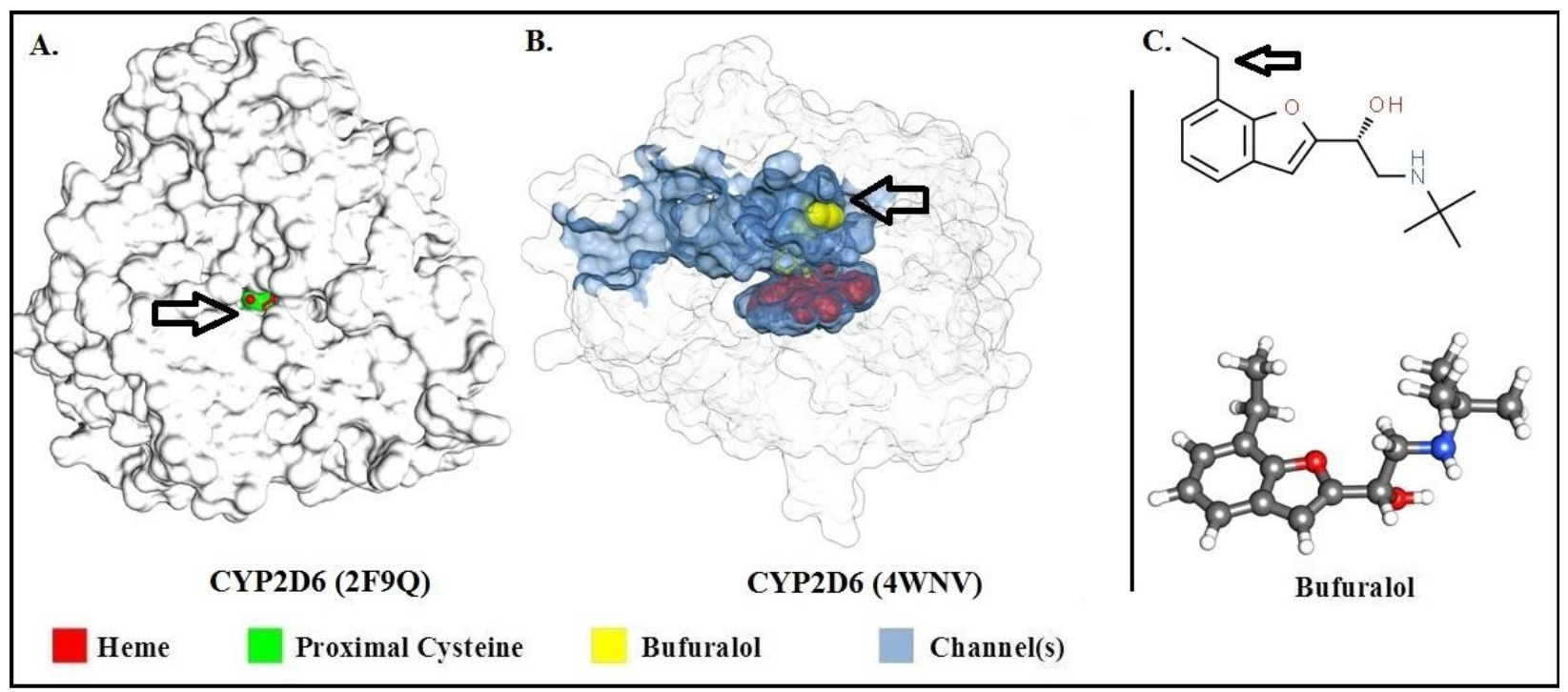

Figure 6: CYP2D6's (4WNV) interaction with bufuralol. Unlike CYP2C9, CYP2D6 has a relatively broader orifice and the channel too is wide enough to allow the entry of substrates like bufuralol. We can observe that the entry from distal pocket is therefore feasible and it can reach quite close to the heme-floor where it could be positioned to be hydroxylated enantioselectively, as the substrate/DROS movement is minimized and the probability for a practical Fe-O species interaction with the activated benzylic carbon goes up significantly. 


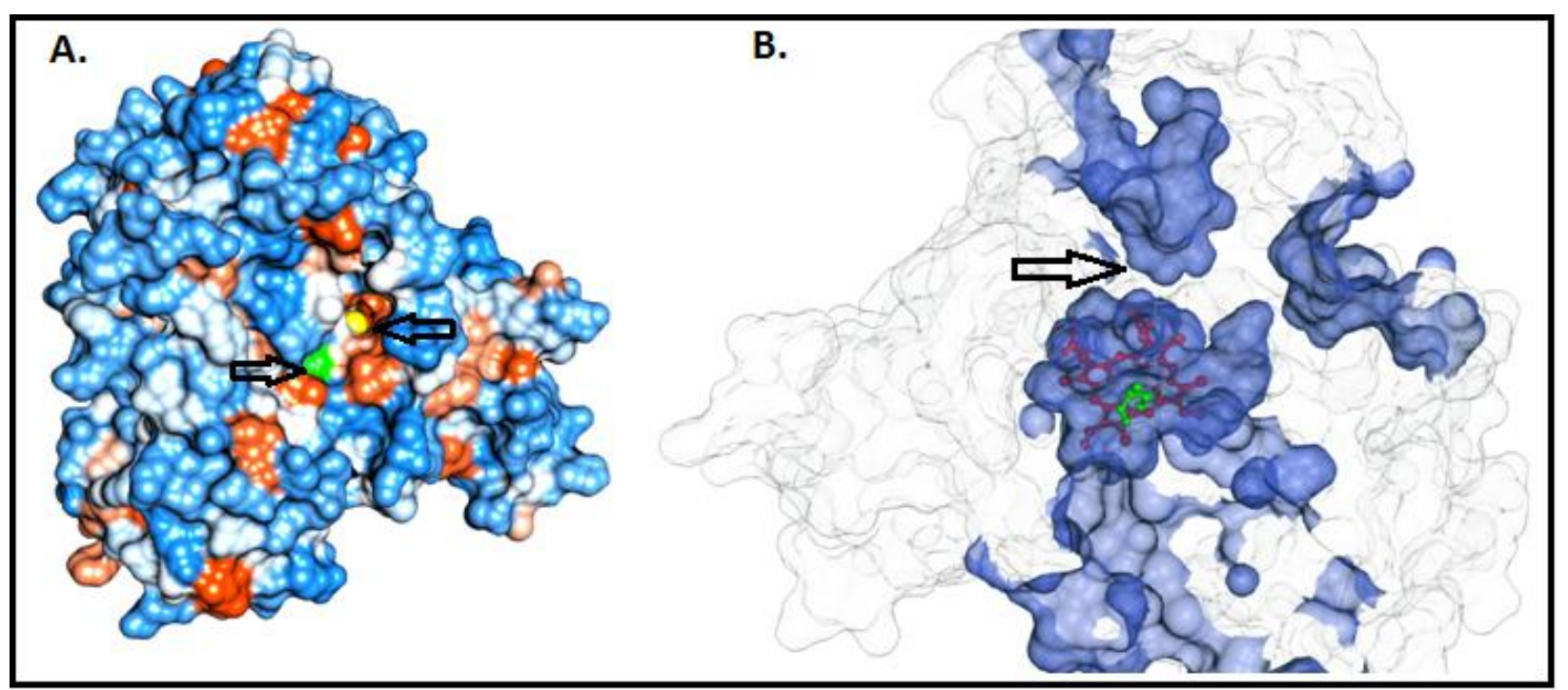

Figure 7: Analysis of CYP2E1's structure. In the proximal view shown in panel A, the proximal cysteine (green) and heme (yellow) are marked. The proximal side has a large hydrophobic cavity. Panel B shows that the distal heme cavity has no connections to any channels opening up on the distal side of heme.

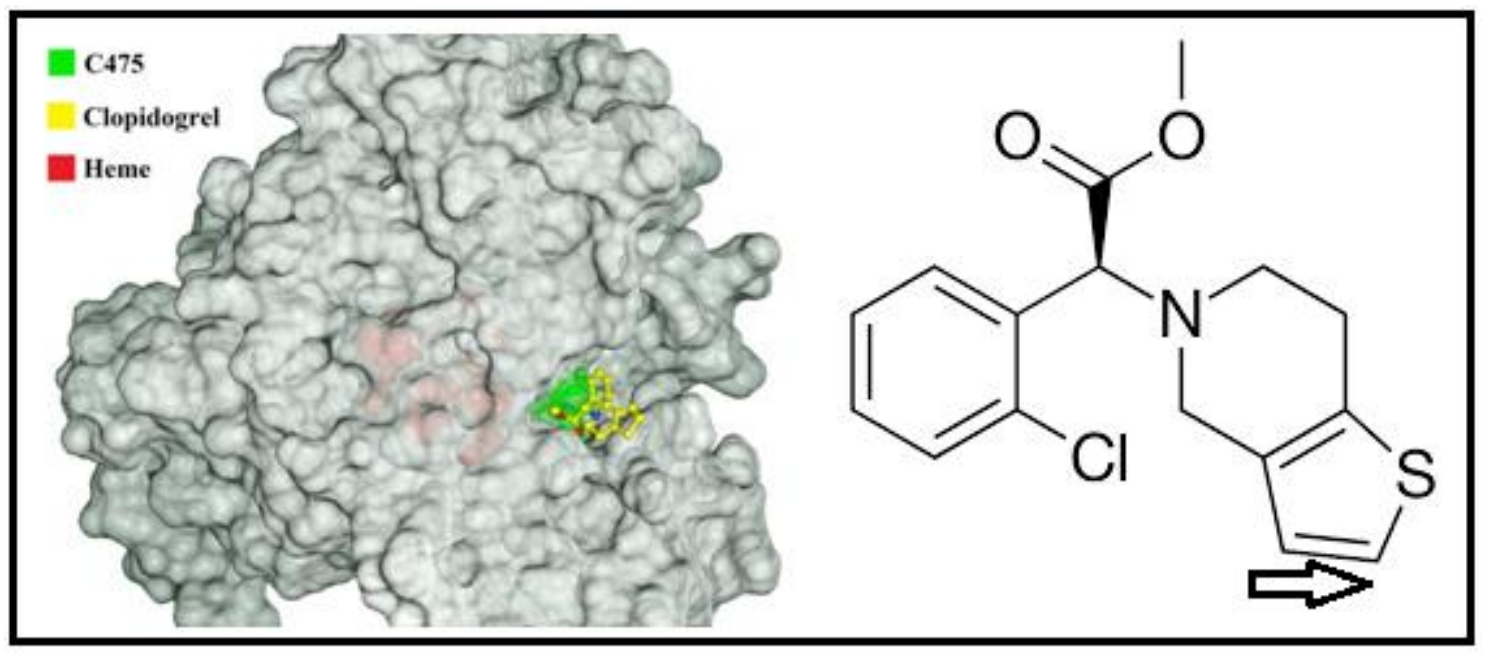

Figure 8: Mutation (C475) on CYP2B6 (4RQL) affecting the activity of/on clopidogrel. C475

is shown to be involved in mechanism based inhibition of CYP2B6 by clopidogrel. It is although clearly observed here that $\mathrm{C} 475$ is located at the surface and clopidogrel interacts with the same feebly. A mutation of C475S avoids inhibition of the enzyme. 


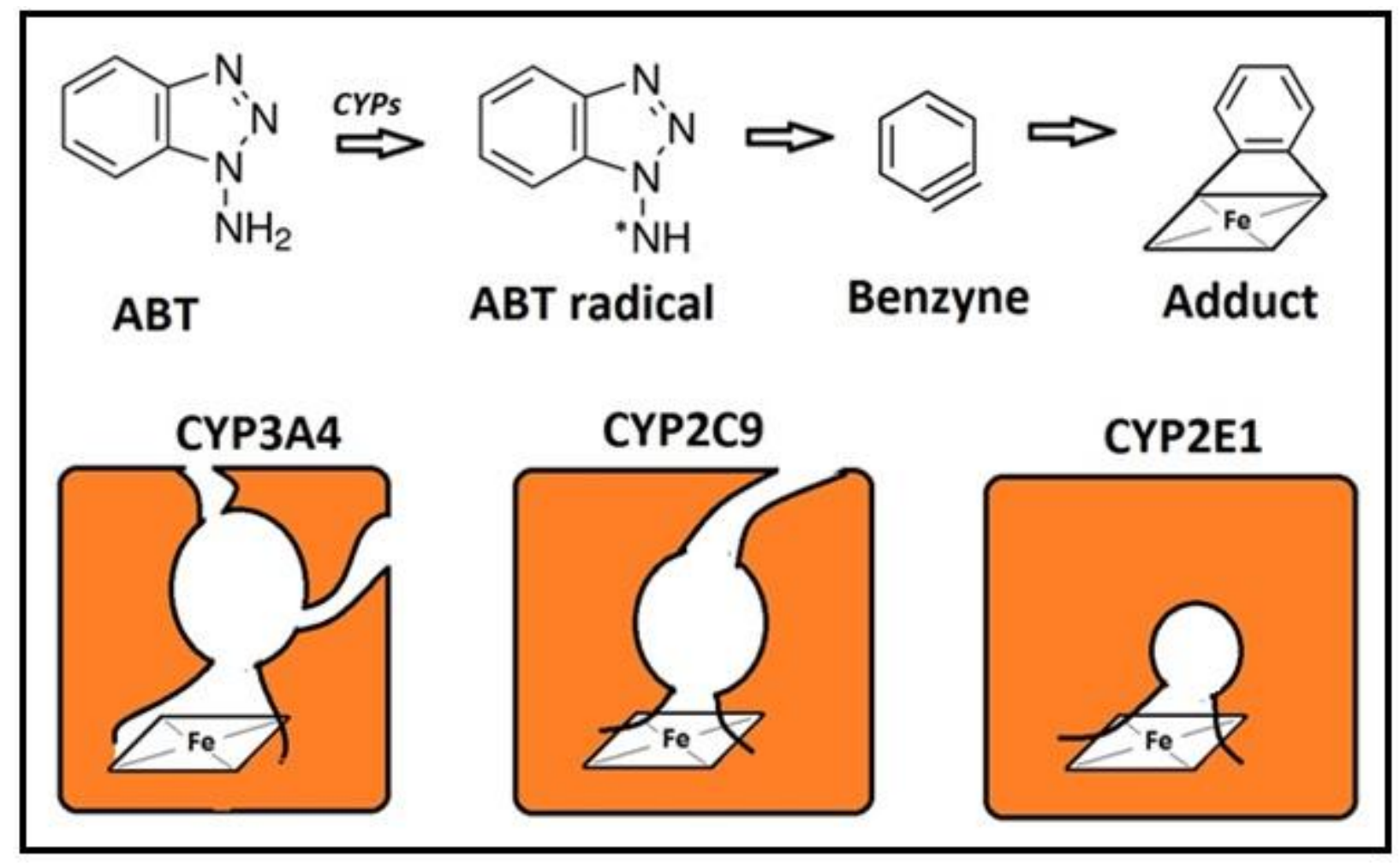

Figure 9: Explaining mechanism-based inaction of CYPs by aminobenzotriazole (ABT). The top panel shows the transformation of native aminobenzotriazole to a much smaller benzyme which forms adduct with the porphyrin ring. The panel below schematically represents the access to the edges of porphyrin as observed upon channel analysis. Evidently, CYP3A4 presents wide access to the edges whereas it is constricted for CYP2C9. CYP2E1 also demonstrates constriction, and the porphyrin edges of CYP2E1 are not so accessible. Moreover, there is no distal channel in CYP2E1 which could connect to the small distal pocket over hemeFe. 


\title{
Supplementary File
}

\section{Murburn precepts for cytochrome $\mathbf{P 4 5 0}$ mediated drug metabolism}

\author{
Abhinav Parashar* ${ }^{1,2} \&$ Kelath Murali Manoj $*^{1}$
}

*Corresponding author, ${ }^{1}$ Satyamjayatu: The Science \& Ethics Foundation,

Snehatheeram, Kulappully, Shoranur-2 (PO), Kerala, India-679122.

murman@satyamjayatu.com ; parashar.abhinav.2008@gmail.com 


\section{Item 1}

Analysis of the soluble P450cam (CYP101) system: Figure S1
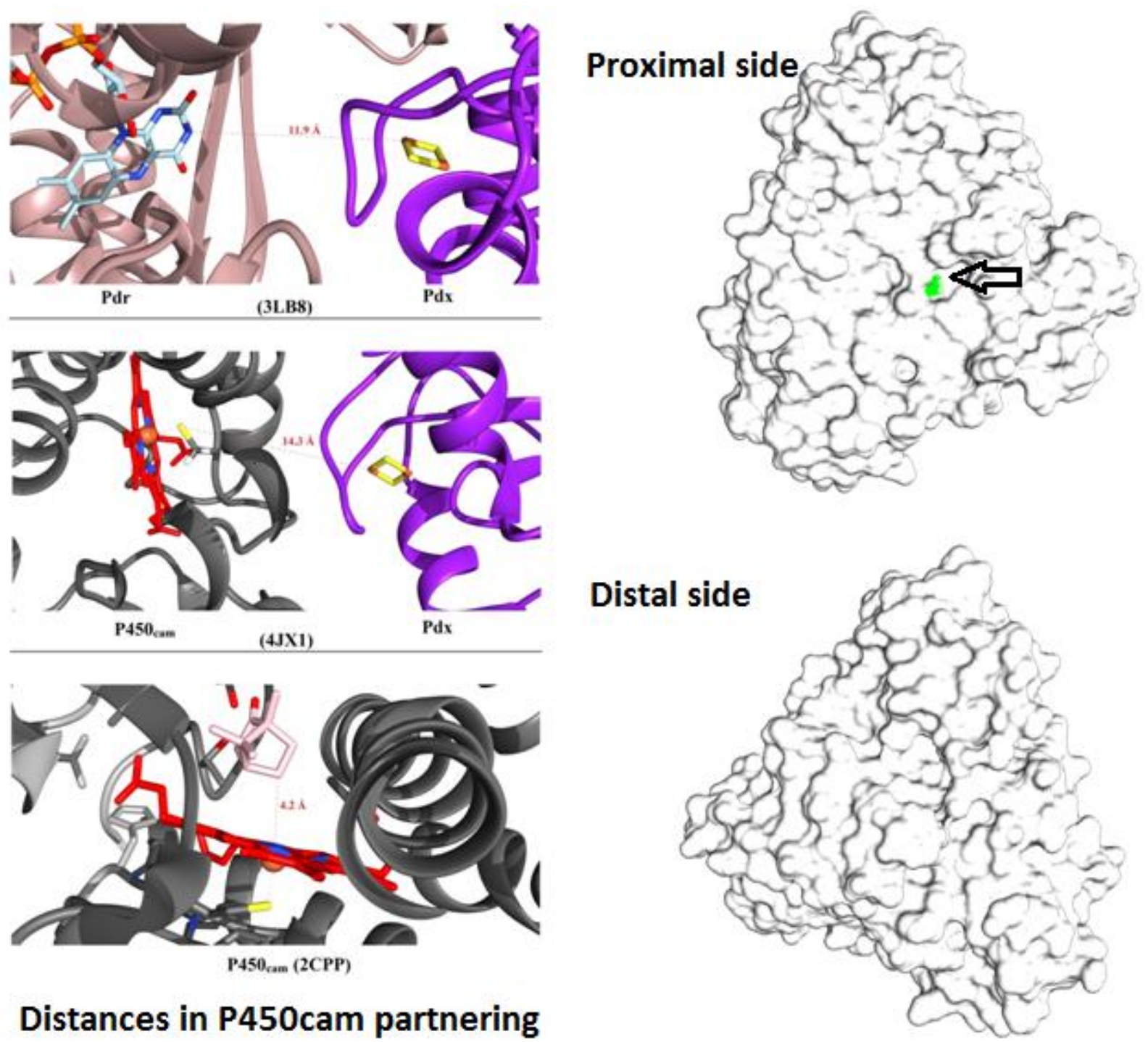

\section{Distances in P450cam partnering}

In the left panels: PdR-Pdx, Pdx-P450cam and P450cam + cam interactions are respectively shown from top to bottom. The distances between the redox centers of PdR-Pdx and Pdx-P450cam are considerably large for proteinprotein complex mediated electron transfers, particularly given the poor redox potential gradient that would exist if the substrate is in an unbound state. In the right panels, the proximal and distal views of P450cam are shown. P450cam does not seem to have an easily accessible channel leading to the distal heme pocket. This would need a repeated opening (for letting camphor in) and closing cum reopening again (for binding-based redox potential shift and letting out the substrate, respectively) type "intelligent" operation by the protein. 

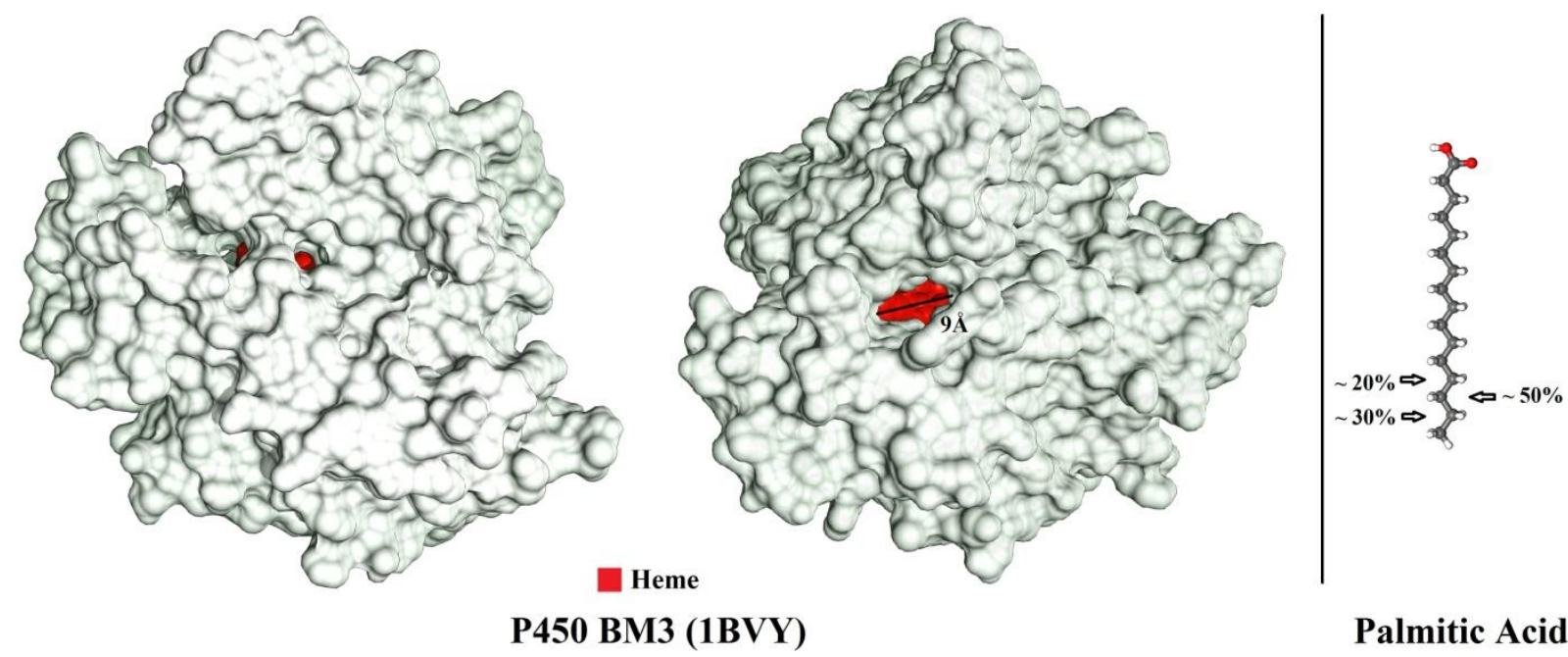

Palmitic Acid

Two distal views of the heme domain of CYPBM3 is shown above. The modest stereo and regio selective hydroxylation of fatty acids by P450BM3 is by virtue of a largely open-bored channel that can allow the fatty acids to enter the heme cavity and enable the presentation of the enatiotopic faces effectively for demarcation by the reactive species. If the reaction was by an oxygen rebound, one would expect hydroxylation predominantly at the first or second carbons, as presenting the 3rd carbon for reactivity at the heme-center would be difficult. Quite simply, such facets are absent in both P450cam and a vast majority of liver microsomal CYPs. 


\section{Item 2}

$C P R+N A D(P) H+C Y P+$ Substrate $(R=$ Methane $)\left(\right.$ Reaction employing $\left.\mathrm{NADPH}+{ }^{*} \mathrm{OH}\right)$

(i) $\mathrm{NADPH}+2 \mathrm{O}_{2} \rightarrow * \mathrm{NADPH}^{+}+2 * \mathrm{O}_{2}^{-}+\mathrm{H}^{+}$[CPR or milieu; -406.5]

(ii) $2 * \mathrm{O}_{2}^{-}+2 \mathrm{H}^{+} \rightarrow \mathrm{H}_{2} \mathrm{O}_{2}+\mathrm{O}_{2}$ [CYP or milieu; -82.7]

(iiia) $\mathrm{Fe}^{3+}+* \mathrm{O}_{2}^{-} \rightarrow \mathrm{Fe}^{2+}+\mathrm{O}_{2}$ [CYP]

(iiib) $\mathrm{Fe}^{2+}+\mathrm{H}_{2} \mathrm{O}_{2} \rightarrow \mathrm{Fe}^{3+}+* \mathrm{OH}+\mathrm{OH}^{-}$[CYP]

(iii) $* \mathrm{O}_{2}{ }^{-}+\mathrm{H}_{2} \mathrm{O}_{2} \rightarrow * \mathrm{OH}+\mathrm{OH}^{-}+\mathrm{O}_{2}[\mathrm{CYP} ;-82.2]$

(iv) $* \mathrm{OH}+\mathrm{RH} \rightarrow \mathrm{ROH}+* \mathrm{H}$ [CYP or milieu; 57.02]

(v) $\mathrm{O}_{2}+* \mathrm{H} \rightarrow{ }^{*} \mathrm{O}_{2}{ }^{-}+\mathrm{H}^{+}$[CYP or milieu; -211]

$\mathrm{RH}+\mathrm{O}_{2}+\mathrm{NADPH} \rightarrow \mathrm{ROH}+\mathrm{NADP}^{+}+\mathrm{OH}^{-}[-747.4]$

In the above, superoxide can be stabilized and released from the CYP too; which can abstract a hydrogen atom from substrate RH, giving peroxide ion and $\mathrm{R}^{*}$. This can react again with peroxide, to give the respective alcohol and hydroxyl radical. For methane, superoxide reaction can be shown in two equivalent ways, of which the second appears more feasible (as both steps are thermodynamically viable):

$* \mathrm{O}_{2}{ }^{-}+\mathrm{RH}+\mathrm{H}^{+} \rightarrow * \mathrm{R}+\mathrm{H}_{2} \mathrm{O}_{2}$ [31.2]

$* \mathrm{R}+\mathrm{H}_{2} \mathrm{O}_{2} \rightarrow \mathrm{ROH}+* \mathrm{OH}[-175.5]$

$* \mathrm{O}_{2}{ }^{-}+\mathrm{RH}+\mathrm{H}^{+} \rightarrow \mathrm{ROH}+* \mathrm{OH}[-144.3]$

$* \mathrm{O}_{2}{ }^{-}+\mathrm{RH} \rightarrow \mathrm{ROH}+{ }^{*} \mathrm{O}^{-}[-80.2]$

$* \mathrm{O}^{-}+\mathrm{H}^{+} \rightarrow * \mathrm{OH}[-64.16]$

$* \mathrm{O}_{2}{ }^{-}+\mathrm{RH}+\mathrm{H}^{+} \rightarrow \mathrm{ROH}+* \mathrm{OH}[-144.3]$

There are also other possible interactions, and the system could go through any of these probabilistic routes:

$* \mathrm{OH}+\mathrm{RH} \rightarrow * \mathrm{R}+\mathrm{H}_{2} \mathrm{O}[-68.7]$

$* \mathrm{R}+* \mathrm{OH} \rightarrow \mathrm{ROH}[-361.1]$

For substitution of a relatively complex molecule like coumarin:

$* \mathrm{O}_{2}{ }^{-}+\mathrm{RH}+\mathrm{H}^{+} \rightarrow \mathrm{ROH}+{ }^{*} \mathrm{OH}\left[3{ }^{\prime} \mathrm{OH}\right.$ coumarin: -212.41$]$

$* \mathrm{O}_{2}{ }^{-}+\mathrm{RH}+\mathrm{H}^{+} \rightarrow \mathrm{ROH}+{ }^{*} \mathrm{OH}$ [7'OH coumarin: -168.56$]$

$* \mathrm{OH}+\mathrm{RH} \rightarrow \mathrm{ROH}+{ }^{*} \mathrm{H}$ [3'OH coumarin: -11.03 ]

$* \mathrm{OH}+\mathrm{RH} \rightarrow \mathrm{ROH}+{ }^{*} \mathrm{H}$ [7' $\mathrm{OH}$ coumarin: 32.82$]$ 


\section{Item 3}

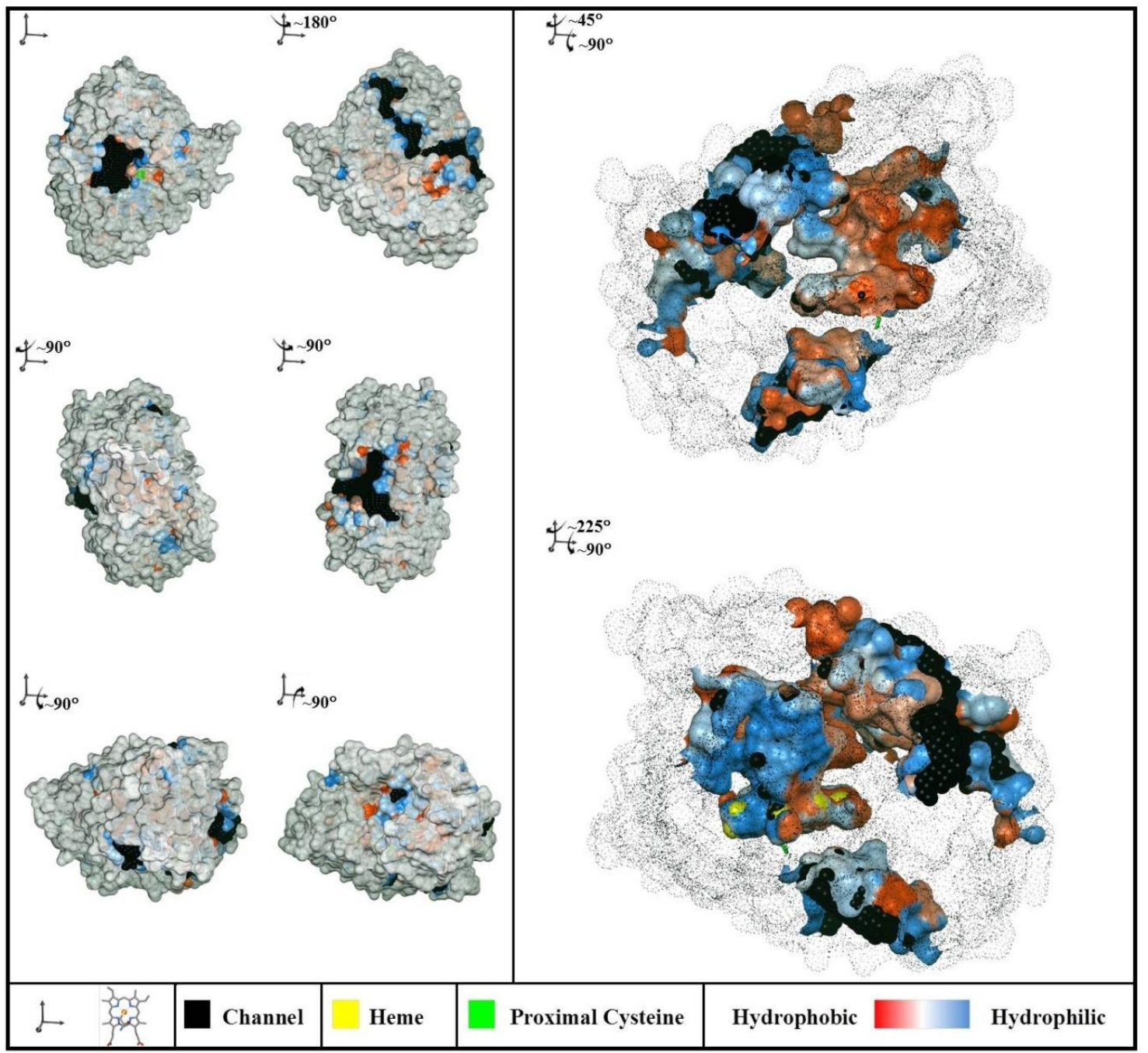

Figure S3: Surface properties and channels in CYP3A4 (3NXU) CYP3A4 has a very high promiscuity and this topographical analysis helps in understanding this nature of 3A4 in purview of murburn. The proximal view (top left) depicts a large channel that is in vicinity to the proximal cysteine and also, has a considerable amount of hydrophobic patch. These features would allow some ligands to interact efficiently at the proximal side of this protein. Since the proximal side is not directly connected to the heme via any channel, the flow of DROS for the reactions at proximal side would be relatively challenging as compared to CYP2E1. Interestingly, CYP3A4 shows three channels which connects to the heme floor. The distal side (top row, second image) shows a series of pockets in continuous connection. The base also shows another channel opening (bottom row, second image). There are two channels which connect to the heme floor from the bottom side and one channel from the distal side, making up three in total. It is although strange that the orifice of either of these channels is not big enough to allow even a moderately sized molecule to enter the large bulbous cavity around the heme floor. To add to the complexity, the cavity on the surface constricts at the junction with the bulb covering the presumed active site of CYP3A4. This therefore would not allow the ligand, be that even smaller in size, to cross this constriction and enter the big bulb. The hydrophobic patches on the surface of CYP3A4, hence, serve as a binding locus for most of its substrate (especially the hydrophobic patch near the bottom region). The channels of CYP3A4 open towards the surface where the ligands have found a hydrophobic domain to adhere. 


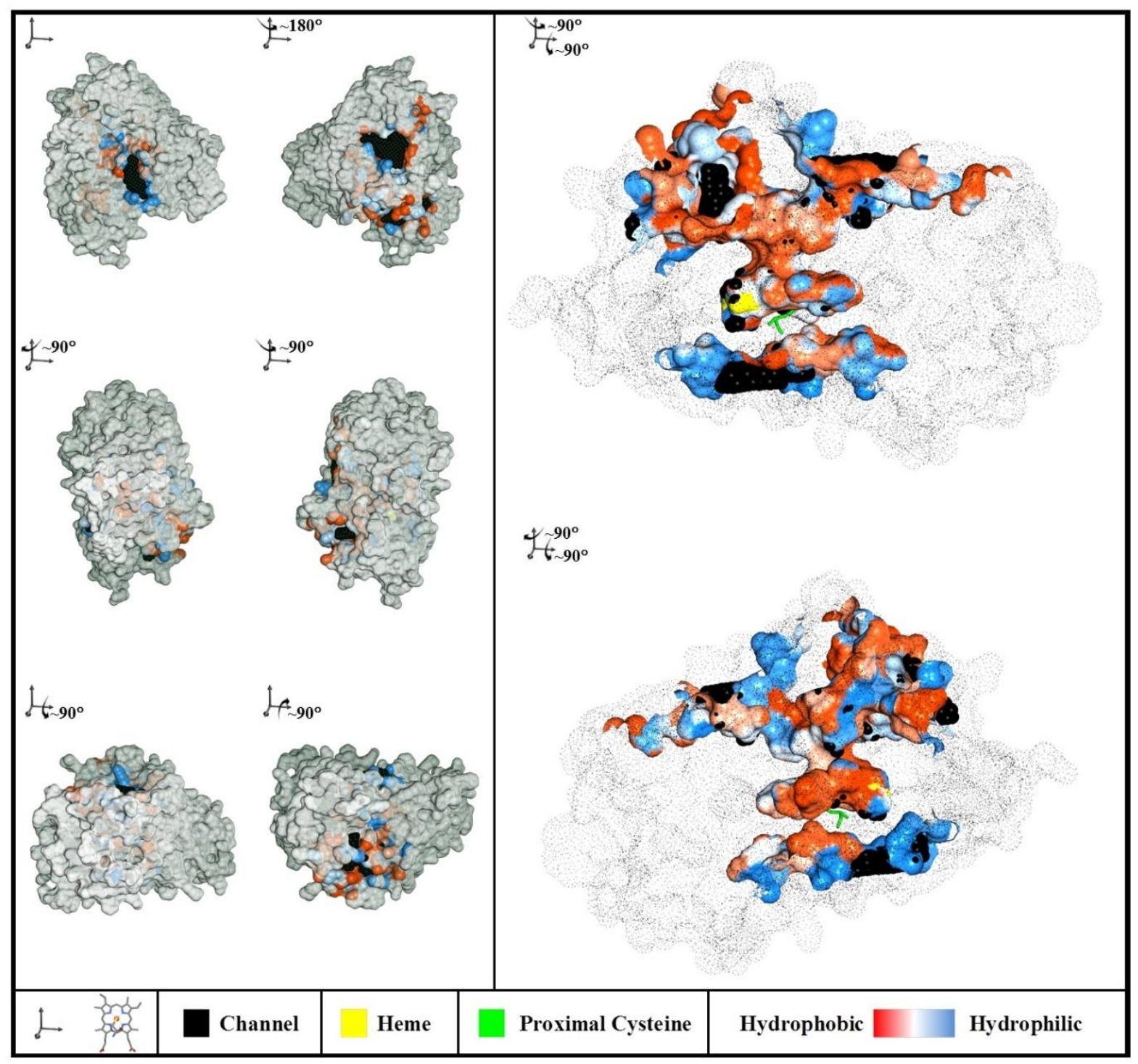

Figure S4: Surface properties and channels in CYP2C9 (1R9O): CYP2C9, another major human liver microsomal CYP, shows two channels from the distal face, and another accessible channel from the proximal face. The protein is shown in white and the channels covered with the solid black hides a significant hydrophobic patch at the entrance of these channels, but the same can be seen by observing the channel views presented on the right (an inside view). CYP2C9 also has a small hydrophobic groove which is internally connected to its bigger counterpart, both of which can be observed at 5 o'clock and 6 o'clock position respectively, in the top row second image (distal view). This groove provides an important ligand binding site on CYP2C9, and majority of the drugs find this as the most favourable locus rather than in the active site (when compared with their binding energies revealed from a previously done docking study). Nevertheless, some of the small sized molecules can still find their way through the channel, which however constricts near the heme floor. A direct entrance of the ligands through the channel present in the center of the distal view is most probable for relatively small volume molecules. Orifice of other channels is relatively smaller. The proximal face does not connect directly to the heme floor, but the proximal cysteine is well on the surface and also there is a small connection with the proximal channel. 


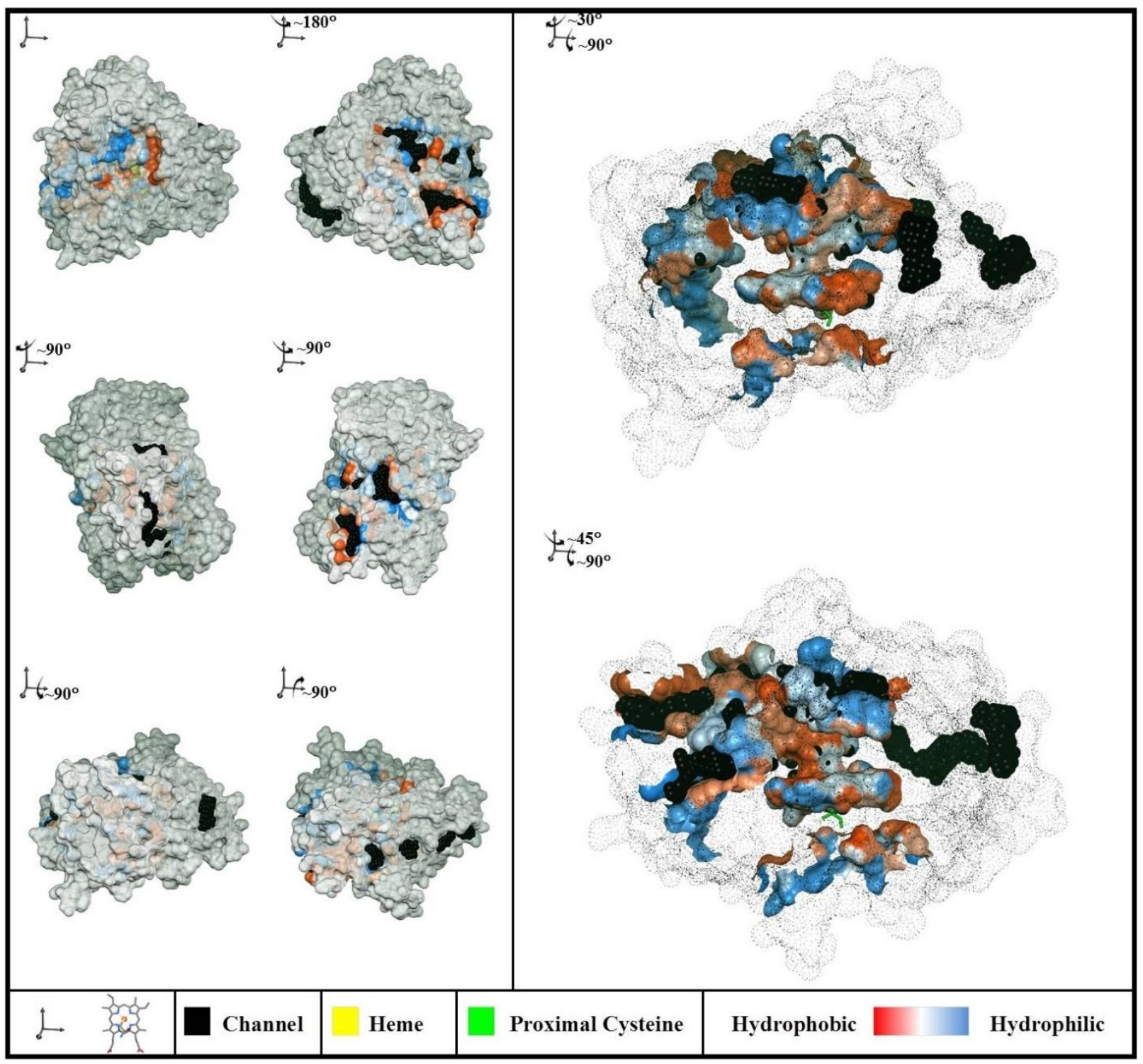

Figure S5: Surface properties and channels in CYP2D6 (4WNV): CYP2D6, unlike CYP2C9, does not show the presence of any channel from the proximal side of the protein. Although, we can certainly observe a hydrophobic region on the right and the left side of the proximal cysteine, which may still serve as a binding locus to certain xenobiotics. The distal side of 2D6, however, has web of channels, and the one at center and at 5 o'clock (observed in second image of first row) are well connected internally and further make route to the heme. Just before the floor of the heme, we do notice slight constriction, but, the channel still remains big enough for small molecules to directly access the heme floor (both images on right hand side). CYP2D6 does not show channels, other than on distal side, which can connect to heme surface. The hydrophobic patches contained in the cavities on surface may still serve to bind ligands. Some of these patches may also present the ligands close to the openings of channels which avails the DROS for reaction. CYP2D6 is known to show enantioselectivity, which can be now understood due to the presence of these channels that can bring forth its substrate in a specific orientation through $\sim 8 \AA$ lumen. 


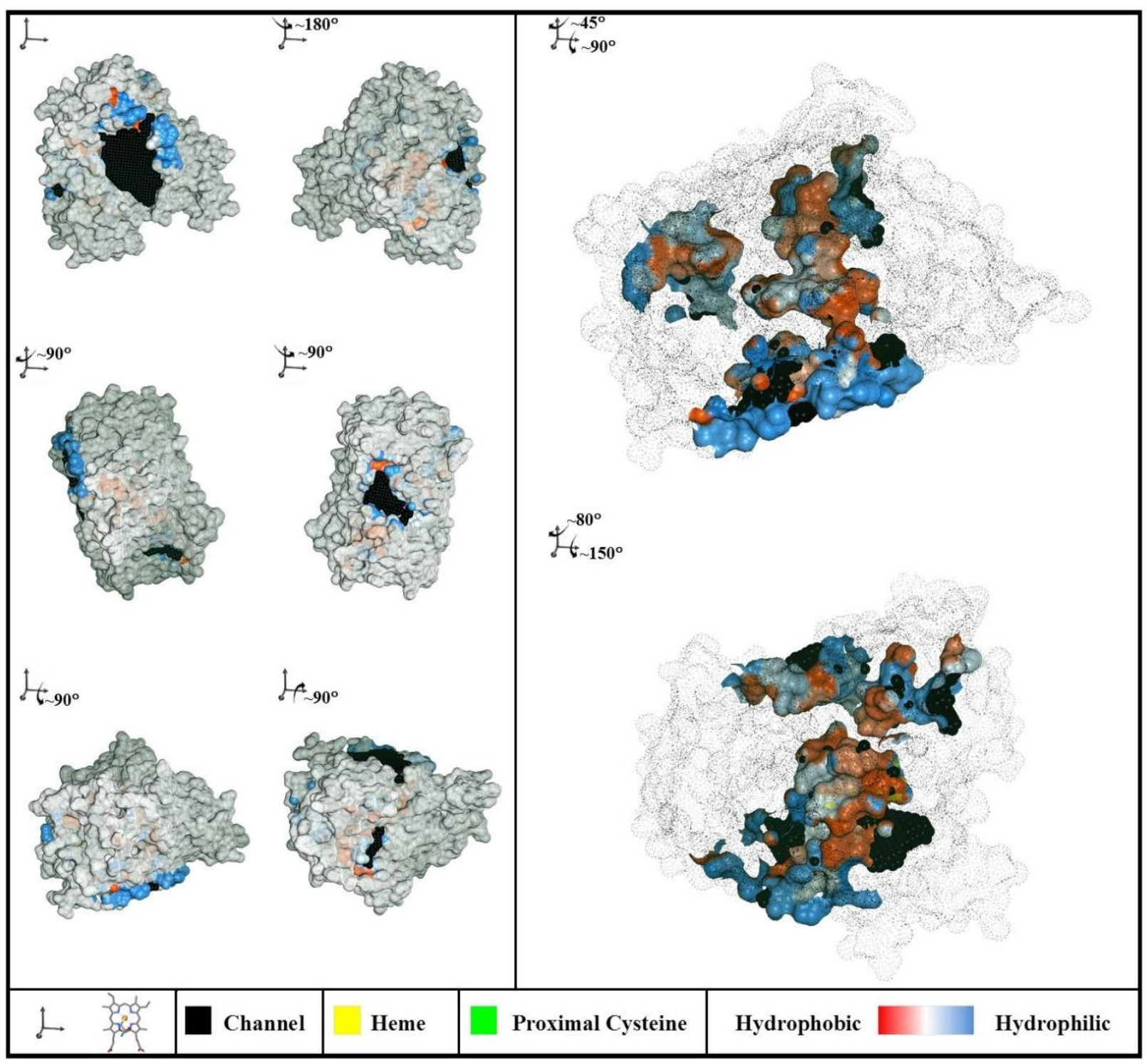

Figure S6: Surface properties and channels in CYP2E1 (3E6I): CYP2E1 is completely opposite to CYP2D6 in the sense that the channel from the distal site does not connect to the heme floor at all. The channel from the proximal side in 2E1 is rather large and it connects directly to heme edge through a large enough channel for DROS to mediate the reactions. The distal view of CYP2E1 shows no channel as well. A cavity observed on the sides of the protein or at the bottom also, does not make it up to the heme floor. CYP2E1 has no access channel other than from the proximal side. This feature of this isoform makes it stand out from the bunch in its reactivity. Most of the substrates of CYP2E1 are small molecules which may find their route through the proximal side, but, there are few which are large and certainly can't make an entry through this channel. Such molecules (hypnotics like zopiclone, etc.) may therefore, find it more feasible to adhere on the surface, where a DROS could further hydroxylate them. 